\title{
Combined pulmonary fibrosis and emphysema syndrome: a radiologic perspective
}

\author{
I.B. Oliva1 1 , F. Cortopassi², C.L. Rochester ${ }^{3}$, A.N. Rubinowitz ${ }^{1}$
}

ABSTRACT: Combined pulmonary fibrosis and emphysema syndrome: a radiologic perspective. I.B. Oliva, F. Cortopassi, C.L. Rochester, A.N. Rubinowitz.

Chronic obstructive pulmonary disease (that includes emphysema) results in significant morbidity and mortality worldwide. Idiopathic pulmonary fibrosis (IPF) is also a chronic and progressive parenchymal lung disease with an average survival of less than 5 years after diagnosis. Combined pulmonary fibrosis and emphysema (CPFE) is an important but still underdiagnosed syn- drome. Its diagnosis is based on the radiological findings at computed tomography which consists of emphysema of the upper lung zones and fibrosis of the lower lung zones. Since this syndrome has a very bad prognosis, even worse than isolated finding of emphysema or fibrosis alone, early recognition and rapid treatment are important. In this article we will review and elucidate the radiologic appearance of this syndrome and highlight its clinical importance.

Monaldi Arch Chest Dis 2011; 75: 4, 220-234.

Keywords: Idiopathic pulmonary fibrosis, Chronic obstructive pulmonary disease, Combined pulmonary fibrosis and emphysema, Computed Tomography.

1 Department of Diagnostic Radiology, Yale New Haven Hospital; Yale University School of Medicine, New Haven, CT,

2 Yale New Haven Hospital; Yale University School of Medicine, New Haven, CT,

3 Section of Pulmonary and Critical Care, Yale University School of Medicine, New Haven, CT; VA Connecticut Healthcare System, West Haven, CT, U.S.A.

Correspondence: Isabel B. Oliva, Assistant Professor of Department of Diagnostic Radiology, Yale New Haven Hospital; Yale University School of Medicine, 333 Cedar St, NP 2 2003, New Haven, CT U.S.A. 06520-8042; e-mail: isabel.oliva@yale.edu

\section{Introduction}

Chronic obstructive pulmonary disease (COPD) and pulmonary fibrosis (PF) are chronic progressive lung diseases both of which account for significant morbidity and mortality. COPD is currently predicted to become the third leading cause of death worldwide in 2020 [1,2]. The impact is so great because it affects such a large population during the prime of their life. Pulmonary fibrosis is a progressive disease with average an survival of 3 to 5 years following diagnosis [3]. Both of these diseases have different etiologies with distinct pathogenic, clinical, functional, radiological, and pathological characteristics. The syndrome of combined pulmonary fibrosis and emphysema (CPFE) is a newly recognized syndrome which has a much worse prognosis than emphysema or fibrosis when occurring in isolation.

Combined pulmonary fibrosis and emphysema syndrome was first described in a series of eight patients by Wiggins et al. in 1990 [4]. Some have questioned whether CPFE is really a new and distinct disease, or simply represents the coexistence of the two distinct pathological alterations. However, more recently, CPFE has been characterized as an individual entity that is separate from both pulmonary fibrosis and emphysema alone because when occurring together they are associated with distinct symptoms and clinical manifestations [5]. Computed tomography (CT) of the chest is the most important modality used in the diagnosis of CPFE. It shows emphysema of the upper lung zones and fibrosis predominating in the lower lung zones. Fibrotic changes are seen on the chest $\mathrm{CT}$ as honeycombing, architectural distortion, reticular markings, traction bronchiectasis, and occasionally ground glass opacities (representing fine fibrosis), all with a peripheral distribution. Clinically, the patients demonstrate severe hypoxemia with normal to slightly reduced lung volumes and severely reduced diffusing lung capacity for carbon monoxide (DLCO). CPFE syndrome is often accompanied by pulmonary arterial hypertension, which worsens with disease progression and negatively impacts patient prognosis.

Given that radiology plays a key role in early diagnosis of CPFE syndrome, our intention is to not only elucidate the clinical manifestations of this disease but also its the radiologic features, reviewing fundamental points and findings of this syndrome.

Pulmonary Fibrosis: definition and background

The American Thoracic Society/European Respiratory Society consensus statement lists sev- 
en idiopathic interstitial pneumonias (IIP's) based on histopathological patterns. The seven clinicopathological entities include: nonspecific interstitial pneumonia (NSIP), organizing pneumonia (OP), acute interstitial pneumonia (AIP), respiratory bronchiolitis-interstitial lung disease (RB-ILD), desquamative interstitial pneumonia (DIP), lymphocytic interstitial pneumonia (LIP), and usual interstitial pneumonia (UIP) [5]. UIP is the most common of the IIP's accounting for 50-60\% of cases [6]. The histological pattern of UIP may develop secondary to dust exposure (e.g., asbestosis), drug toxicity, and collagen-vascular diseases (e.g., rheumatoid arthritis), or it can be seen in the setting of chronic hypersensitivity pneumonitis [5]. In many cases, after detailed clinical evaluation, no etiology is found so the morphologic pattern of UIP is considered synonymous with the clinical syndrome of idiopathic pulmonary fibrosis (IPF).

Histopathologic characteristics of UIP include heterogeneous areas of pulmonary fibrosis with fibroblastic foci in association with areas of normal lung, interstitial inflammation, and honeycomb changes with the temporal heterogeneity being the most characteristic feature $[5,7]$. There may also be mild inflammatory cell infiltration to a lesser extent [8]. The factors that initiate and maintain the inflammatory and fibrotic responses observed in IPF remain unknown but the current hypothesis is that IPF pathogenesis involves different mechanisms that include repetitive lung injury, deposition of collagen and extracellular matrix, inflammation, proliferation of fibroblasts, in the setting of an inappropriate healing response [9].

Idiopathic pulmonary fibrosis is a chronic and progressive fibrosing interstitial lung disease with a highly variable clinical course [10-12] and an average survival of less than 5 years after diagnosis. IPF has a worse prognosis when compared with other causes of pulmonary fibrosis. It affects approximately $14-20$ per 100,000 people in the general population $[13,14]$ and currently has no curative treatment. Lung transplant is an option for select patients and can help increase short term survival but is not without its own complications.
The diagnosis of IPF is based on clinical, radiographic, and histopathologic characteristics and the accuracy increases with multidisciplinary discussion between pulmonologists, radiologists, and pathologists experienced in the diagnosis of interstitial lung disease $[12,14]$. According to the official ATS/ERS/JRS/ALAT 2011 consensus the diagnosis of IPF requires: exclusion of other known causes of interstitial lung disease; presence of a UIP pattern on high-resolution computed tomography (HRCT) in patients not subjected to surgical lung biopsy; or specific combinations of HRCT and surgical lung biopsy pattern in patients who have undergone lung biopsy [12] (table 1). Common clinical features include progressive dyspnea, dry cough, and the presence of basilar 'velcro' crackles on physical exam. Digital clubbing and signs of cor-pulmonale may also be present. IPF is rare before the age of 50 and is more prevalent in men, with the majority of patients having a history of cigarette smoking [15-18].

High-resolution computed tomography plays a vital role in the diagnosis of IPF and can help distinguish UIP from other IIPs [19]. When classic features of UIP are present on HRCT, tissue biopsy of the lungs is not needed. If HRCT does not demonstrate the classic features, a definitive pathological diagnosis of UIP can be made from open or video-assisted thoracoscopic biopsy. The presence of coexisting pleural abnormalities such as pleural plaques, calcifications, or significant pleural effusion suggests an alternative etiology for the UIP pattern.

The course of IPF is variable, with few patients remaining stable for long periods of time while a significant proportion developing progressive dyspnea. The dyspnea is particularly present during exertion and worsens in periods of acute exacerbation. It can resolve rapidly or progress to respiratory failure and death, especially when associated with pulmonary arterial hypertension [20].

Pulmonary arterial hypertension (PAH) is defined as a mean pulmonary artery pressure of $>25$ $\mathrm{mm} \mathrm{Hg}$ at rest. When present secondary to underlying pulmonary fibrosis, there is an increase in the al-

\section{Table 1. - High-resolution CT criteria for UIP pattern}

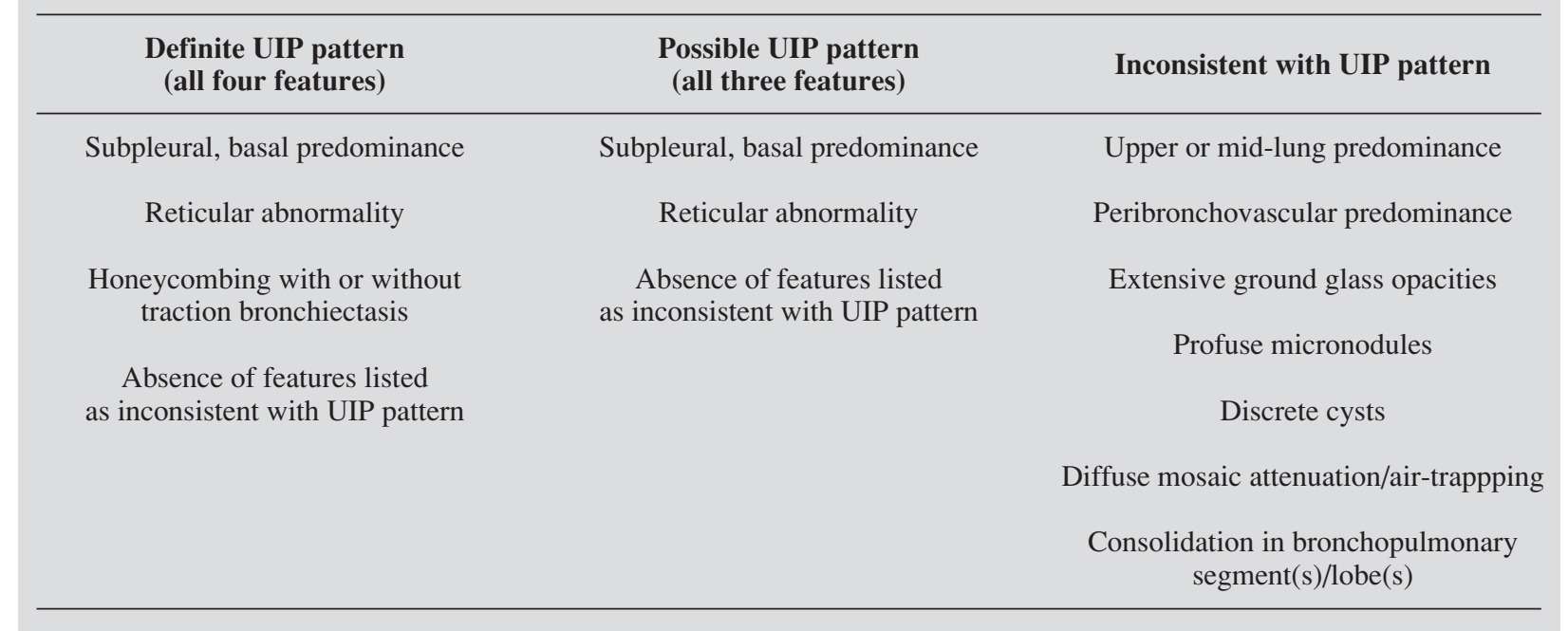


ready high mortality rate in these patients [21]. Early studies showed that patients with IPF had higher mean pulmonary arterial pressures compared to patients with other non-IPF interstitial lung diseases [22]. Pulmonary fibrosis probably contributes to the pathogenesis of pulmonary arterial hypertension as a result of chronic alveolar hypoxia and vascular remodeling, but the most important mechanism is likely the reduction in the pulmonary vascular bed secondary to extension of fibrosis itself [23]. Patients with pulmonary fibrosis are also at increased risk for pulmonary embolism, which is probably secondary to endothelial damage [24].

\section{COPD: definition and background}

Chronic obstructive pulmonary disease was the $12^{\text {th }}$ leading cause of disability in the world during the 1990's [25] but is estimated to increase in prevalence, with current predictions that it will be among the top five leading causes of death by 2030 [26]. It results in great economic and social burden that is both substantial and increasing because it affects a population during their most productive work years. In the United States, COPD was responsible for 126,000 deaths in 2005 [27]. The estimated prevalence of COPD varies from 7 to $19 \%$ in several well-conducted studies around the world [28-33]. However COPD still remains underdiagnosed, especially because it often stays clinically silent until it is at an advanced and irreversible stage $[34,35]$.

COPD is a preventable disease characterized by airflow limitation that is not fully reversible and is staged on the basis of the severity of irreversible airflow obstruction quantification [36]. The airflow obstruction is secondary to an abnormal inflammatory response of the lungs to noxious particles or gases, primarily caused by tobacco smoking. It is usually progressive and can be the end result of multiple distinct events. Other important risk factors include occupational and organic dusts exposures, socio-economic status, and genetic factors. COPD has a variable natural history with different individuals developing distinct clinical courses [37]. With the progression of the disease, COPD patients demonstrate compromised gas exchange leading to respiratory failure with poor prognosis. Death is frequently secondary to associated co-morbidities that are also related to cigarette smoking such as heart disease and lung cancer $[36,38]$.
Repetitive airway injury from inhaled tobacco smoke toxins, chronic oxidative stress, and imbalance of proteinases and antiproteinases trigger an inflammatory response that leads to structural changes in the airways and lung parenchyma [39, 40]. COPD comprises pathological changes in four different compartments: central airways, peripheral airways, lung parenchyma, and pulmonary vasculature. The main physiologic abnormalities in COPD are mucous hypersecretion and ciliary dysfunction; airflow limitation and hyperinflation; gas exchange abnormalities; systemic effects and pulmonary hypertension [41].

Emphysema and obstructive airway disease are two commonly described subtypes of COPD. Considerable overlap with different proportions of each of these processes exists in COPD subjects [42]. Clinically, patients with COPD are classified according to Global Obstructive Lung Disease (GOLD) stages based on the severity of airway obstruction [36] but individuals with the same GOLD stage can exhibit markedly different degrees of emphysema radiographically. Emphysema is a pathologic diagnosis defined as "permanent abnormal enlargement of the airspaces distal to the terminal bronchiole associated with destruction of their walls and no obvious fibrosis" [43]. There are three main subtypes of emphysema based on the anatomic distribution: centriacinar (also known as centrilobular), panacinar (also known as panlobular), and paraseptal (table 2). These subtypes of emphysema are better distinguished morphologically during early stages but when they become more severe, their distinction becomes more difficult.

Centriacinar emphysema primarily affects the respiratory bronchioles and alveoli in the central portion of the secondary pulmonary lobule. This subtype of emphysema predominantly involves the upper lung zones and typically results from cigarette smoking. With increasing severity of centriacinar emphysema, destruction progresses to involve the entire secondary pulmonary lobule, making it more difficult to distinct from the pancinar subtype of emphysema.

Panacinar emphysema destroys the entire secondary pulmonary lobule uniformly creating multiple areas of decreased lung attenuation with paucity of vessels in the affected regions. It predominates in the lower lobes. This type of emphysema is classically associated with alpha- 1 antitrypsin deficiency but can be seen without protease

Table 2. - Types of pulmonary emphysema

\begin{tabular}{lccccc}
\hline Emphysema & Involvement & Distribution & Etiology & Wall & Bulla \\
\hline Centriacinar & Center of SPL & Upper lobes & Cigarette smoking & Absent & Common \\
\hline Panacinar & Entire SPL & Lower lobes & $\begin{array}{c}\text { Alpha 1 antitrypsin deficiency, } \\
\text { smokers, age or drug related }\end{array}$ & Absent & Uncommon \\
\hline Paraseptal & Distal SPL & Upper lobes and subpleural & Cigarette smoking or idiopathic & Thin & Common \\
\hline SPL = secondary pulmonary. & & & &
\end{tabular}


deficiency in smokers, elderly patients, and in association to certain drugs [43].

Paraseptal emphysema predominantly involves the alveolar ducts and sacs at the distal aspect of the acini with the areas of destruction often marginated by interlobular septa. It can be an isolated finding in young patients often associated with spontaneous pneumothorax or can be seen in older patients with centrilobular emphysema [43, 44]. This type of emphysema is usually seen in association with the centriacinar type in patients who are cigarette smokers but can also be idiopathic in etiology.

Pulmonary hypertension is present in a significant proportion of patients with advanced COPD due to hypoxic vasoconstriction and secondary remodeling of distal small pulmonary arterial branches. The loss of pulmonary capillary bed in emphysema can also contribute to increased pressure in the pulmonary circulation $[45,46]$. The progression of the pulmonary arterial hypertension usually leads to elevated right heart pressures, right ventricular hypertrophy, ultimately resulting in right-sided cardiac failure (cor pulmonale).

\section{Combined pulmonary fibrosis and emphysema (CPFE)}

The combination of pulmonary fibrosis and emphysema was initially thought to be an incidental coexistence of the two diseases and it is still unclear whether both entities coexist by coincidence with each one having distinct pathogenesis, or if some individuals share a common pathway that leads to both fibrosis and emphysema. Animal models suggested a shared mechanism through which cigarette smoke leads to both pulmonary emphysema and fibrosis [47-49]. Such theory has yet to be demonstrated in human subjects however several studies have demonstrated an increased prevalence of IPF in patients with smoking history, suggesting this may indeed be a common pathogen [15-18].

Nonetheless, CPFE has been treated as a distinct disease after Cottin, et al. in 2005 presented a case series in heavy smokers [50]. Patients with combined pulmonary fibrosis and emphysema (CPFE) syndrome demonstrate clinically severe hypoxemia and decreased DLCO with normal to mildly reduced lung volumes. They often have severe secondary pulmonary arterial hypertension, which worsens the prognosis dramatically $[50,51]$.

In the retrospective study conducted by Cottin et al. in 2005 [50], all of the 61 patients were smokers or ex-smokers and most were males, with a mean age of 65 years. The CPFE syndrome was diagnosed by chest computed tomography. This study was one of the first to describe several clinical characteristics of this syndrome. Dyspnea on exertion was present in all patients; bibasilar crackles in $87 \%$ of patients; clubbing in $43 \%$ of patients; and pulmonary arterial hypertension present in $47 \%$ of patients at diagnosis and in $55 \%$ during follow-up. Patients were followed in this study for a mean of $2.1 \pm 2.8$ years after diagnosis.
Survival was $87.5 \%$ at 2 yrs and $54.6 \%$ at 5 yrs, with a median survival of 6.1 yrs. The presence of PAH at diagnosis was a critical determinant of prognosis in this syndrome.

Recently Cottin et al., not only confirmed but also demonstrated in a retrospective multicenter study conducted in 40 patients (38 males; age $68 \pm$ 9 years; 39 smokers) with CPFE and pulmonary arterial hypertension (confirmed by right heart catheterization), that higher pulmonary vascular resistance, higher heart rate, lower cardiac index and lower carbon monoxide diffusion transfer were associated with increased mortality [52]. This study provides several new and important insights. For example, they found that the mean time to diagnose PAH after diagnosing CPFE was 16 months, suggesting that pulmonary arterial hypertension occurs rapidly after diagnosing CPFE. They also showed that patients with CPEF who develop pulmonary arterial hypertension have a worse prognosis with an estimated survival of only $60 \%$ at 1 year.

Pulmonary arterial hypertension is one of the leading causes of symptoms and negatively impacts the prognosis in these patients to a level much worse than that seen among patients with either pulmonary fibrosis or emphysema alone. Literature has shown that at the time the diagnosis of CPFE is made, $47 \%$ of patients are found to have PAH with the percentage increasing with progression of disease [50-52]. It still remains uncertain if $\mathrm{PAH}$ is a response to CPFE alone or a product of emphysema or fibrosis separately.

Spirometry and lung volume components of pulmonary function testing (PFT) in patients with CPFE are usually normal or demonstrate only mild obstructive or restrictive pattern. The basis for this finding, despite the presence of severe underlying parenchymal lung disease may be the opposing physiologic forces of emphysema, which leads to outflow obstruction and hyperinflation, as opposed to fibrosis which decreases lung compliance, decreases lung volumes, and increases outward tethering of small airways [53]. This may be one of the reasons why this syndrome remains underdiagnosed until an advanced stage, when it is already associated with severe PAH. However, the diffusing capacity component of PFT's is typically severely impaired due to loss of intact alveolar-capillary surface area for gas exchange, increased diffusion distance across alveolar-capillary bed, and impaired pulmonary capillary blood flow. It is typical for CPFE patients to demonstrate hypoxemic respiratory failure with significantly reduced diffusing capacity and normal to only mildly reduced lung volumes [54].

\section{Radiology Perspective}

\section{Chest $x$-ray}

Chest radiographs are a standard part of the routine clinical evaluation of subjects with COPD and IPF. Such images are not expensive, are readily available, and involve minimal radiation expo- 
sure when compared with computed tomography (CT) [55].

The chest x-ray of patients with pulmonary emphysema usually demonstrates the combination of increased lung volumes seen as flattening of the diaphragms with right diaphragm's height measuring less than $2.7 \mathrm{~cm}$ on the lateral projection, increased sternodiaphragmatic angle measuring more than 90 degrees, widening of the retrosternal clear space measuring more than $4.4 \mathrm{~cm}$ when measured $3 \mathrm{~cm}$ below the manubrial-sternal junction, increased AP diameter; and upper lobe predominant destruction manifested by relative increased lucency and paucity of vessels in the lung apices and apparent increased interstitial markings at the lower lung zones (fig. 1). Hyperinflation also results in a narrowed, elongated cardiomedistinal silhouette but this is a secondary sign that is neither specific nor sensitive for emphysema [56$60]$. Visualization of associated bullae is diagnostic of emphysema but is seldom seen radiographically. A sensitivity of $80 \%$ has been reported when these findings are used in diagnosis but the likelihood of diagnosis based on chest x-ray depends on the severity of disease with mild forms being almost impossible to detect [61] (fig. 2).

Approximately $10 \%$ of patients with IPF have normal chest radiography $[62,63]$, particularly in early stages of the disease (fig. 3). The radiographic appearance of IPF is nonspecific and correlates poorly with histological findings and severity of disease [6]. When abnormal, chest x-ray may show lower lobe and peripherally predominant reticular markings associated with decreased lung volumes and relative sparing of the lung apices (fig. 4). With more advanced disease, lung volumes become even smaller and the reticular markings progress from fine to coarse. Lower lobe predominant cystic spaces, which represent traction bronchiectasis and/or honeycombing, may also be apparent. The disease classically starts at the posterior costophrenic sulci, which are better assessed on the lateral radiograph.

While chest radiographs are neither sensitive nor specific in diagnosing emphysema or pulmonary fibrosis, when evaluating CPFE syndrome the sensitivity is even lower because the presence of increased lung volumes seen in patients with emphysema is usually masked by the decreased volumes secondary to the concomitant pulmonary fibrosis resulting in normal lung volumes. Other findings of each disease separately may help in the diagnosis but since the lung volumes play an important role in diagnosing each entity separately, with the loss of this finding, accuracy decreases even more.

Some findings that may provide clues to the presence of underlying CPFE include: increased lucency of the upper lungs which is seen in patients with emphysema, in conjunction with increased reticular markings in the lower lobes, that is characteristic of patients with pulmonary fibrosis (fig. 5). However, chest x-rays are of limited value and insensitive in diagnosing this syndrome with computed tomography remaining the most sensitive and specific method of diagnosis.

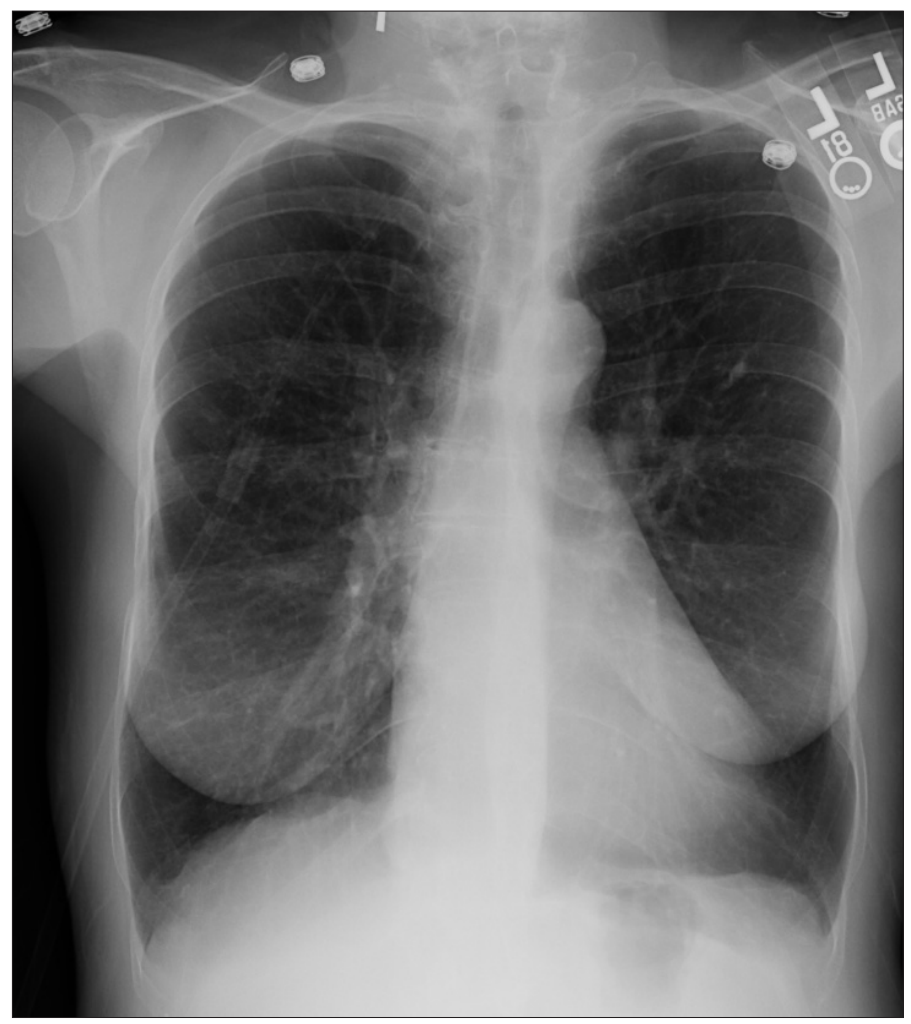

(a)

Fig. 1. - Frontal radiograph of the chest (a) shows upper lobe predominant pulmonary parenchyma destruction due to emphysema seen as lucency and paucity of vessels in upper lung zones. The lateral projection demonstrates flattening of the diaphragms, widening of the retrosternal clear space, and increased AP diameter of the thorax. 


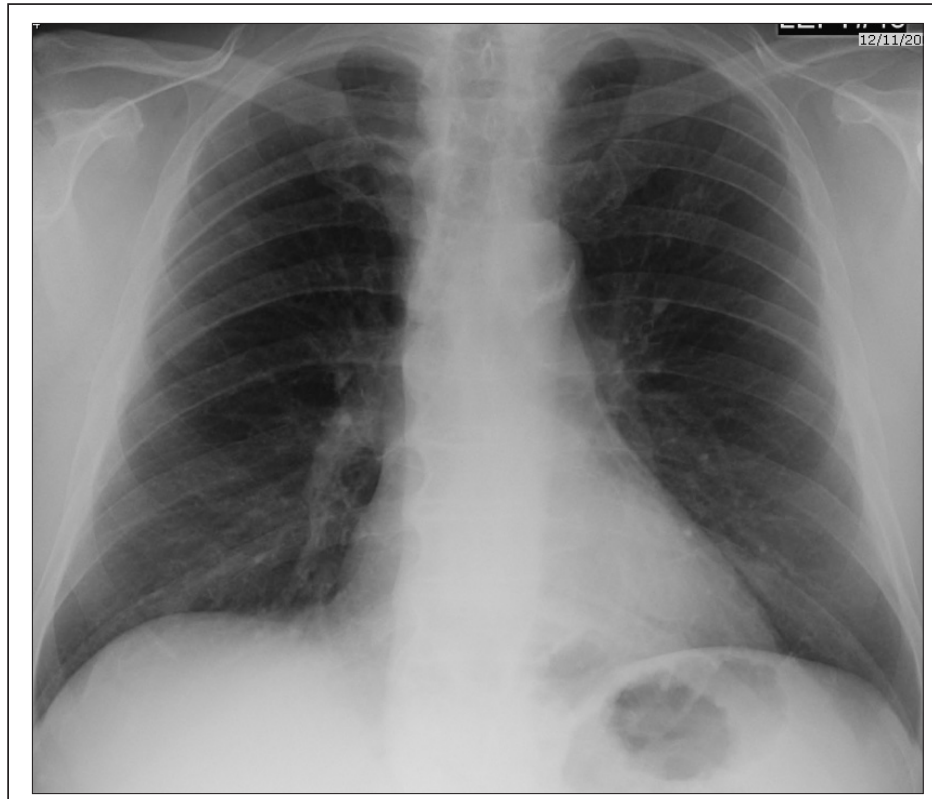

(a)
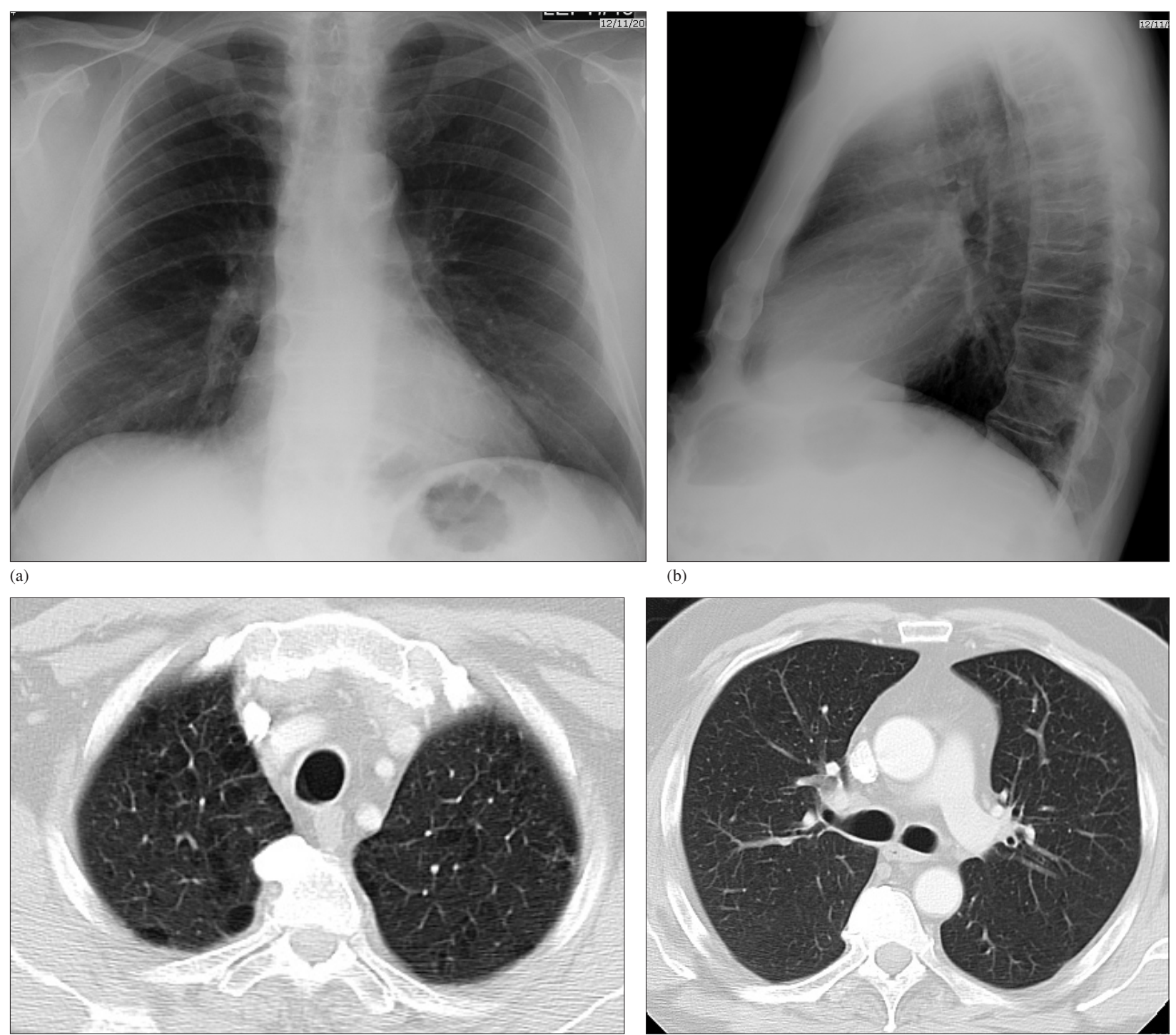

(b)

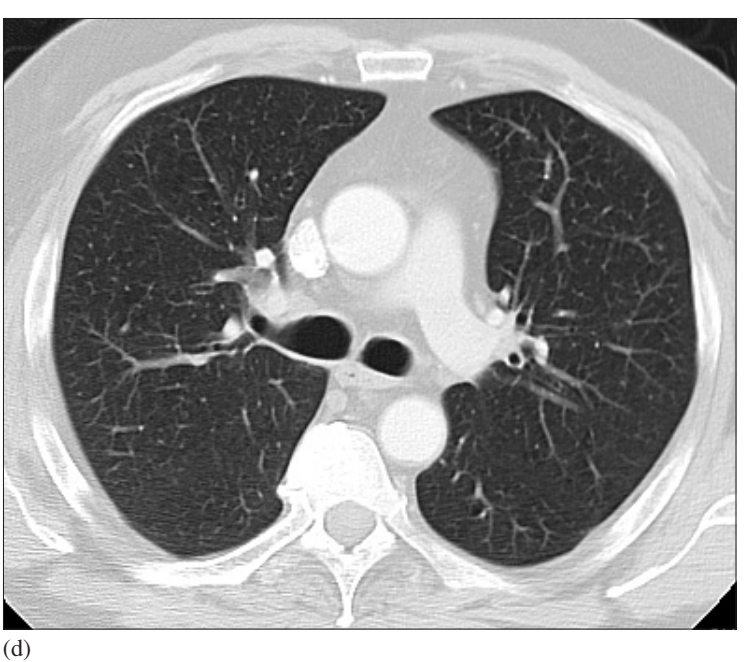

Fig. 2. - Normal frontal (a) and lateral (b) radiographs of the chest in a patient with mild pulmonary emphysema. Two axial images from the chest $\mathrm{CT}$ of the same patient demonstrate upper lobe predominant emphysema.

\section{Computed Tomography}

Computed Tomography is much more expensive than radiographs and exposes the patients to significantly higher radiation doses with mean effective dose using a 64-slice CT scanner of approximately $19.9 \mathrm{mSv}$ [64]. On the other hand, with the advancement of technology, the scanners have become faster and are now able to provide the same image quality with less radiation exposure. CT is as widely available as chest X-rays and remains the most accurate diagnostic modality for patients with pulmonary emphysema and fibrosis. It is much more sensitive and specific in diagnosing and classifying pulmonary emphysema when compared to chest radiography and was recently proven to reduce mortality when used for lung cancer screening [65], which these patients are at increased risk of.

Emphysema is characterized on high resolution computed tomography (HRCT) by areas of abnormal low attenuation contrasted by the normal surrounding lung parenchyma [66-68]. Areas of centriacinar emphysema are seen as focal lucency centered in the middle of the secondary pulmonary lobule, surrounding the centrilobular artery, and without definable walls (fig. 6,7). This type of emphysema is typically seen in cigarette smokers and has an upper lobe predominance. Panacinar emphysema is seen as widespread abnormal low attenuation areas marginated by the interlobular septa and also centered on the centrilobular artery. It maintains the polyhedric shape of the secondary pulmonary lobule and predominates in the lower lobes (fig. 8). Paraseptal emphysema involves the distal aspect of the secondary pulmonary lobule and therefore has a subpleural distribution. It has an elongated shape with perceivable thin walls, which generally correspond to the interlobular septa. With paraseptal emphysema, there is a single row of subpleural cystic spaces (bullae). This is in contrast to honeycombing which is secondary to pulmonary fibrosis in which, by definition, there are at least 2 rows of subpleural cysts as well as 


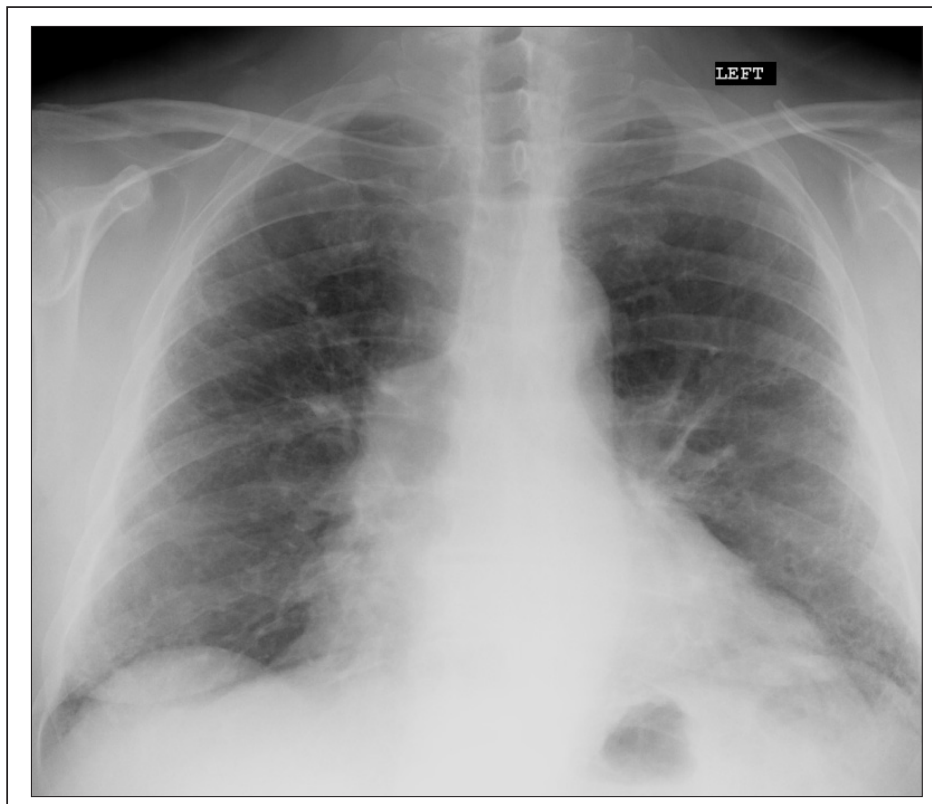

(a)
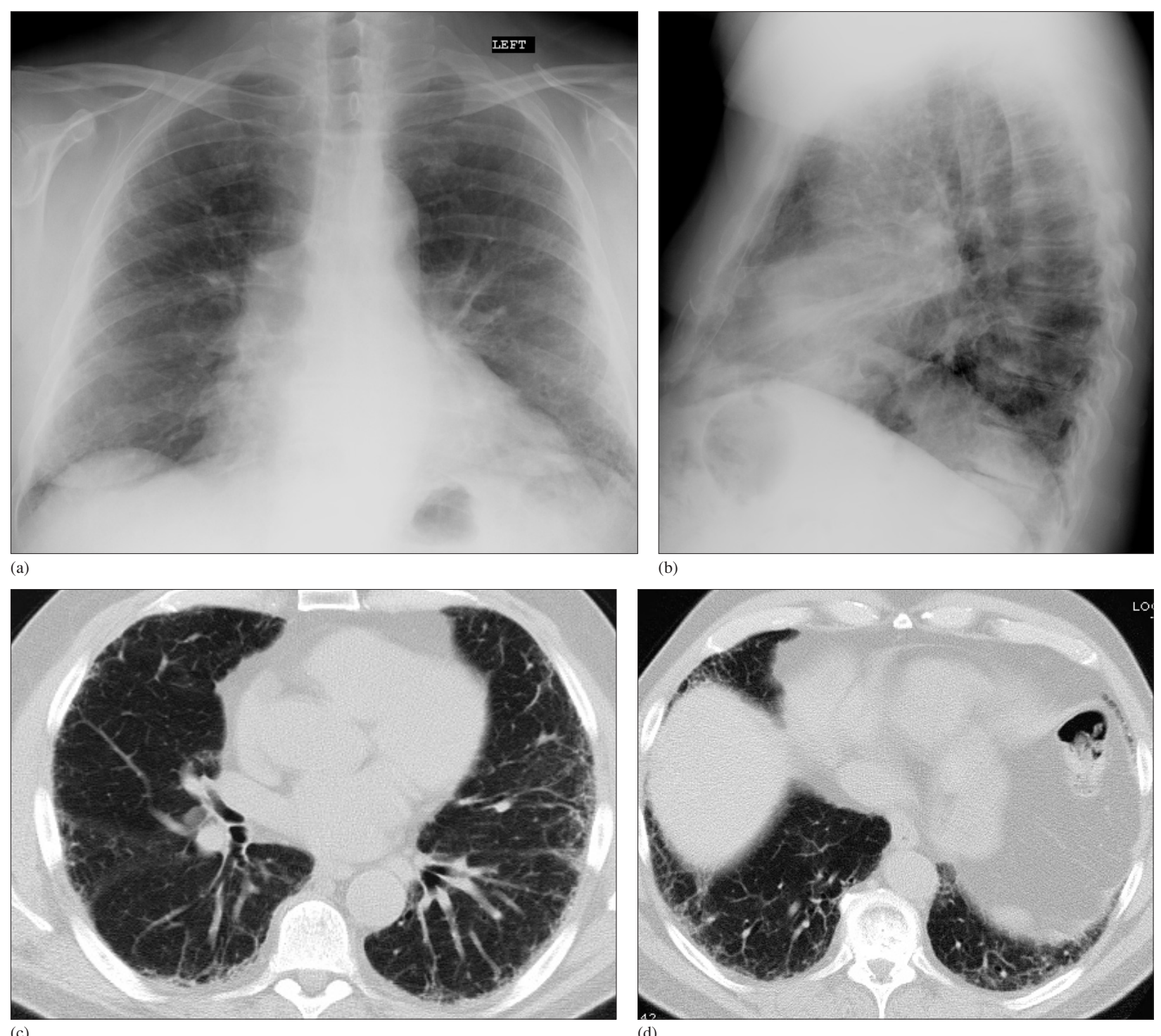

(c)

(d)

Fig. 3. - Normal chest radiograph $(\mathrm{a}, \mathrm{b})$ of a patient with early stage of pulmonary fibrosis. Two axial images from the chest CT of the same patient demonstrating lower lobe predominant reticular markings.

other associated findings of fibrosis (ie: architectural distortion and traction bronchiectasis). Paraseptal emphysema predominates in the upper lobe. When the involved area is larger than $1 \mathrm{~cm}$ in diameter, it is termed a bulla (fig. 9). Bullae are diagnostic of emphysema but are seldom seen on chest radiograph or $\mathrm{CT}$.

Computed tomography scanning of the chest allows quantitative assessment of the extent and severity of pulmonary emphysema as well as elucidating additional features such as the distribution ( $e g$, apical, basal, diffuse) and subtype ( $e g$, centriacinar, panacinar, paraseptal) cof emphysema [69]. Visual scoring by one or more observers [70] was the initial approach utilized when evaluating CT scan data in patients with pulmonary emphysema. As with any subjective form of evaluation, interobserver variability remains a concern. In a study of severe COPD patients [71], interobserver agreement was good for the overall severity of emphysema but was poor in the determination of lobar predominance of emphysema.
Many studies have used CT of the chest to quantify the extent and severity of emphysema and to document progression, but this ability depends on several technical factors including: scanner calibration, collimation, threshold values, window settings, radiation dose, phase of respiratory cycle, reconstruction algorithm, and use of intravenous contrast [72-77]. Subjective quantification of emphysema is the simplest method and is based on visual assessment of the CT images [78-80]. Each part of the lung that appears emphysematous is graded from 1 to $4 \quad(1=1 \%$ to $25 \%$, $2=26 \%$ to $50 \%, 3=51 \%$ to $75 \%$, and $4=76 \%$ to $100 \%$ of the area) with the total score expressed as percentage of total lung involved at that assigned level $[81,82]$.

Conventional chest CT and HRCT are also much more sensitive than routine chest radiography when assessing patients with IPF, and their findings correlate well with symptoms and pulmonary function test results [83]. It has also been proven that the extent of ground glass opacity cor- 

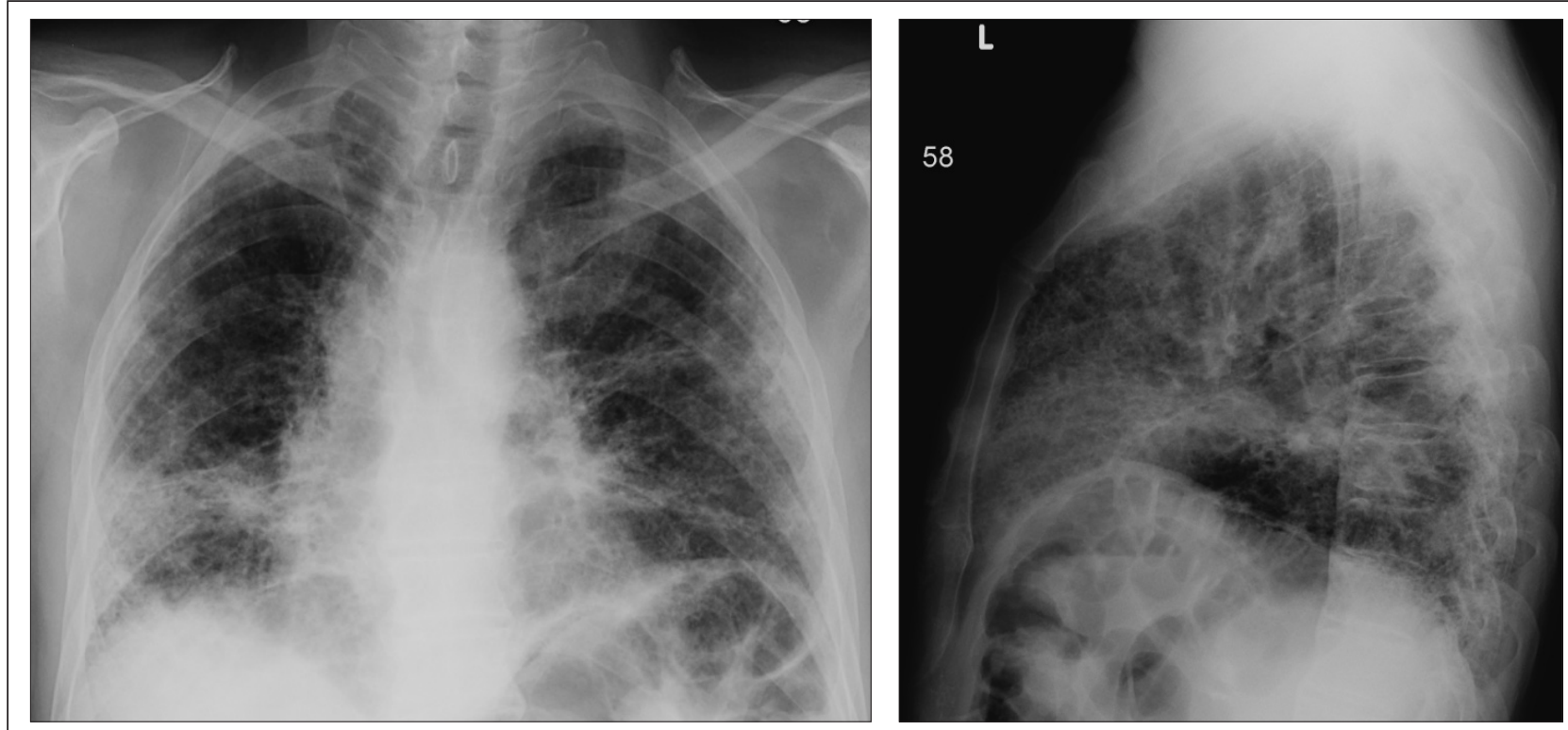

(a)

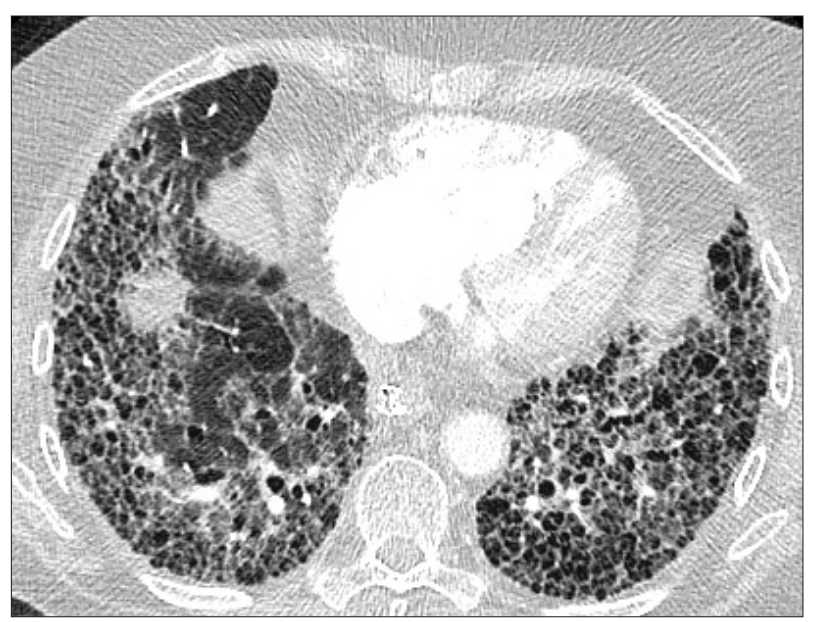

Fig. 4. - Frontal (a) and lateral (b) radiographs of the chest in a patient with idiopathic pulmonary fibrosis demonstrating decreased lung volumes and lower lobe predominant increased reticular markings with relative sparing of the upper lobes. Axial (c) and coronal reformatted (d) CT images of the same patient better depict the peripheral and lower lobe predominant involvement by fibrosis with honeycombing formation.

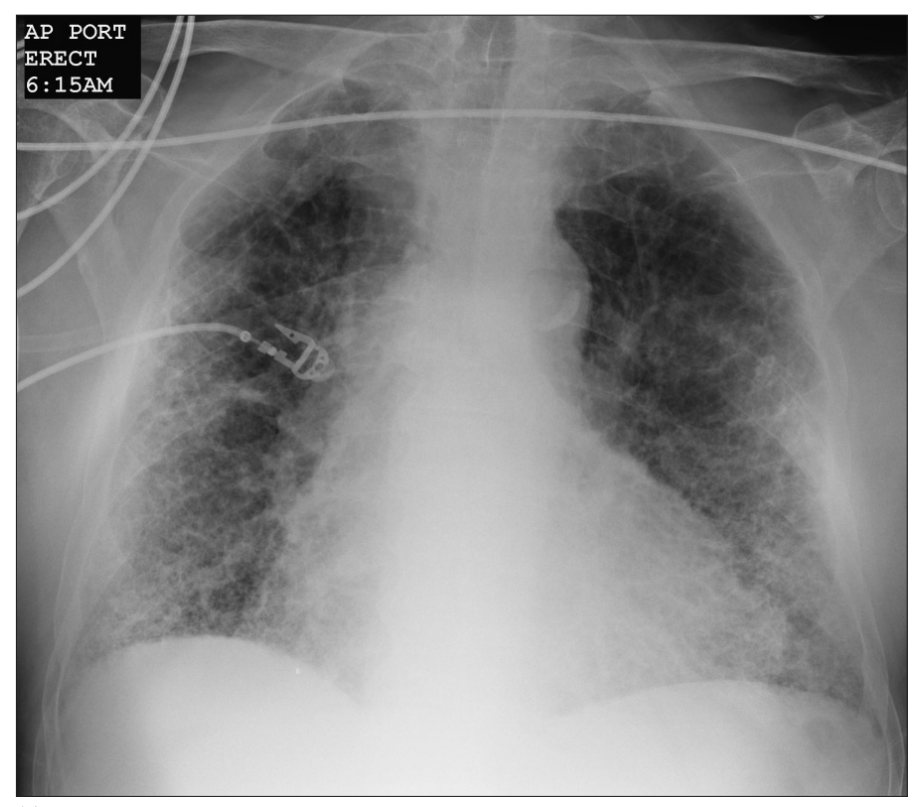

(a)

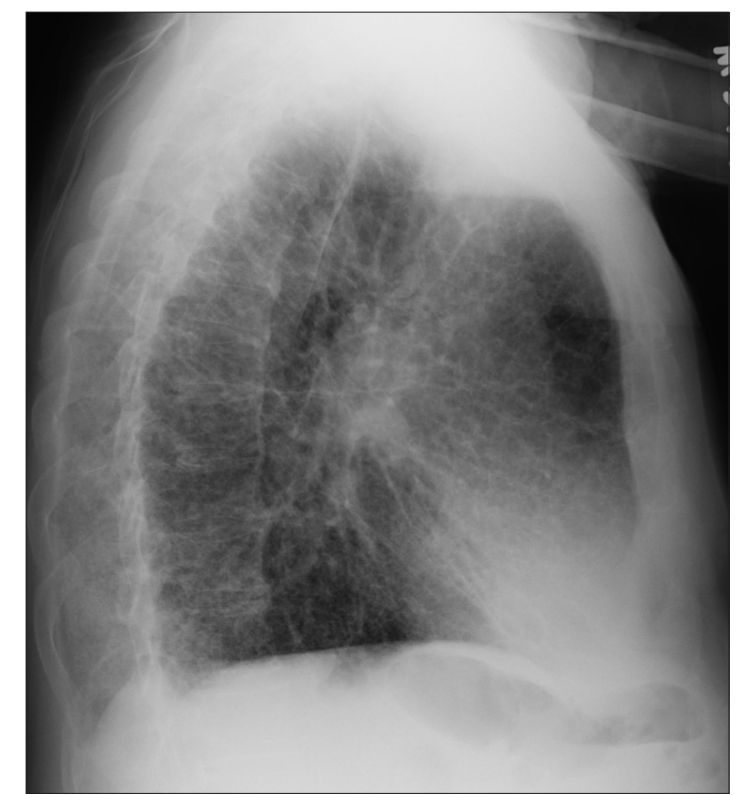

(b)

Fig. 5. - Chest x-rays of a patient with combined pulmonary emphysema and fibrosis syndrome. The lung volumes are normal but the frontal radiograph (a) shows lower lobe predominant reticular markings in conjunction with increased lucency of the upper lobes. The lateral projection (b) demonstrates relative flattening of diaphragms and mildly increased retrosternal clear space. 

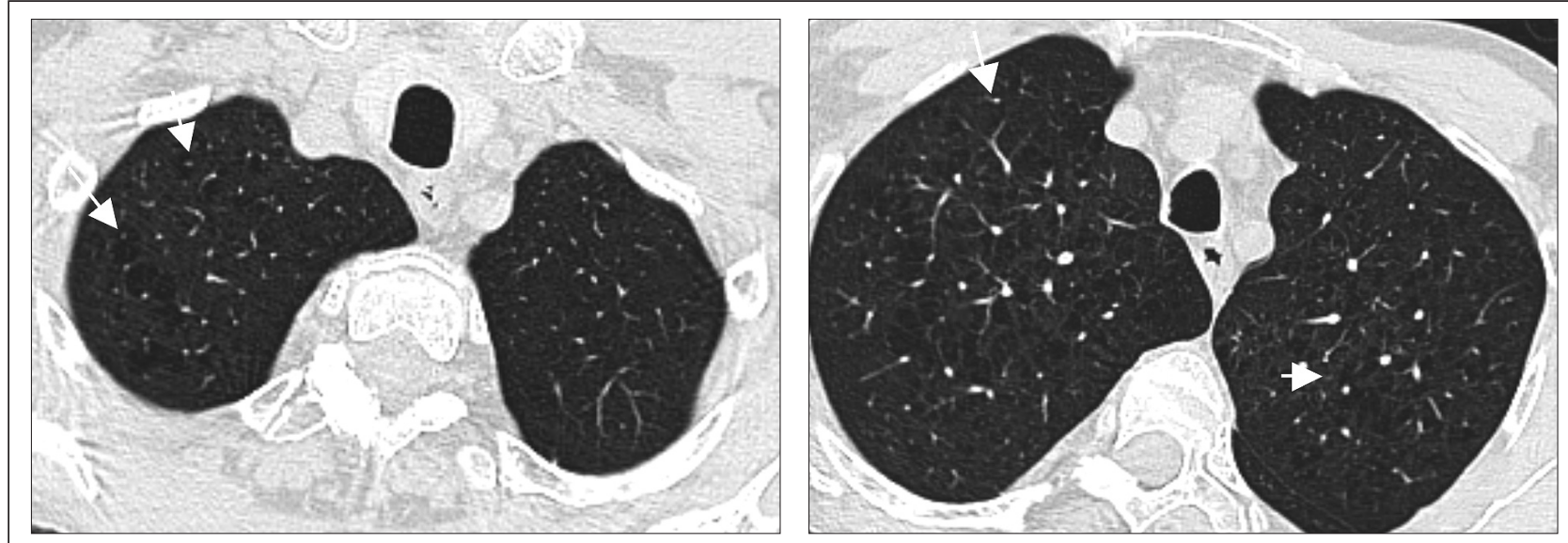

(b)

Fig. 6. - Axial CT images (a, b) of a patient with centriacinar emphysema demonstrating multiple areas of increased lucency involving the secondary pulmonary lobule, centered around the centrilobular artery (white arrows). Note the absence of perceivable walls in the lucent areas.

relates well with the severity of dyspnea and reduction in carbon monoxide diffusing capacity (DLCO), with patients having lower DLCO demonstrating more extensive ground glass opacities by CT [84].

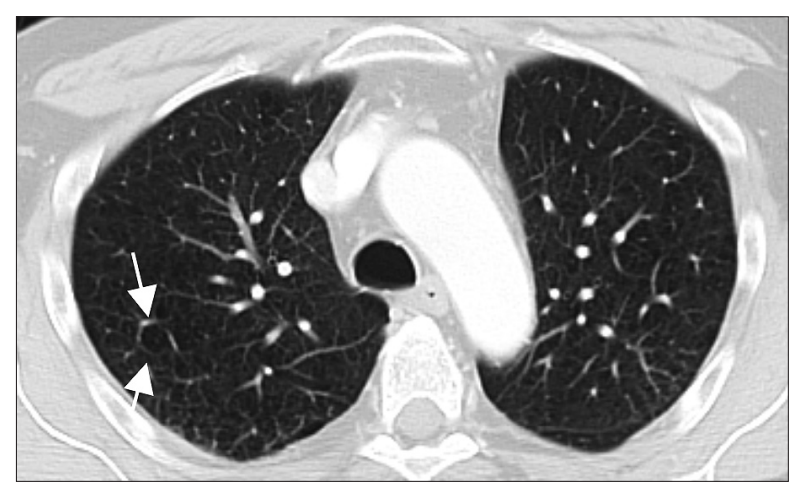

Fig. 7. - Single CT image of a patient with centriacinar emphysema shows the central involvement of the secondary pulmonary lobule with preservation of its polyhedral shape. The interlobular septa appear as walls surrounding the lucent area (arrow) and the centrilobular artery is seen in the middle of it.
Computed tomography of patients with IPF demonstrates lower lobe and peripherally predominant intra and inter-lobular septal thickening, traction bronchiectasis, honeycombing and architectural distortion, all reflecting underlying parenchymal fibrosis (fig. 10). Honeycombing is the most reliable CT finding of fibrosis. Ground glass opacities may also be appreciated, especially early in the course of the disease, or during acute exacerbations, but are never the dominant finding in patients with idiopathic pulmonary fibrosis in the chronic progressive stage. The ground glass opacities can either represent active alveolitis or very fine fibrosis. Thin section CT images can sometimes help distinguish between the two. In about $70-95 \%$ of patients, reticulations involve mainly the subpleural areas and have the classic apicobasal gradient of severity with the abnormality being worse at the lung bases, particularly at the costophrenic angles $[19,85,86]$. Because this is a restrictive lung disease, decreased lung volumes result in elevation of the hemidiaphragms with decreased craniocaudal dimension, a typical finding in patients with lung fibrosis.

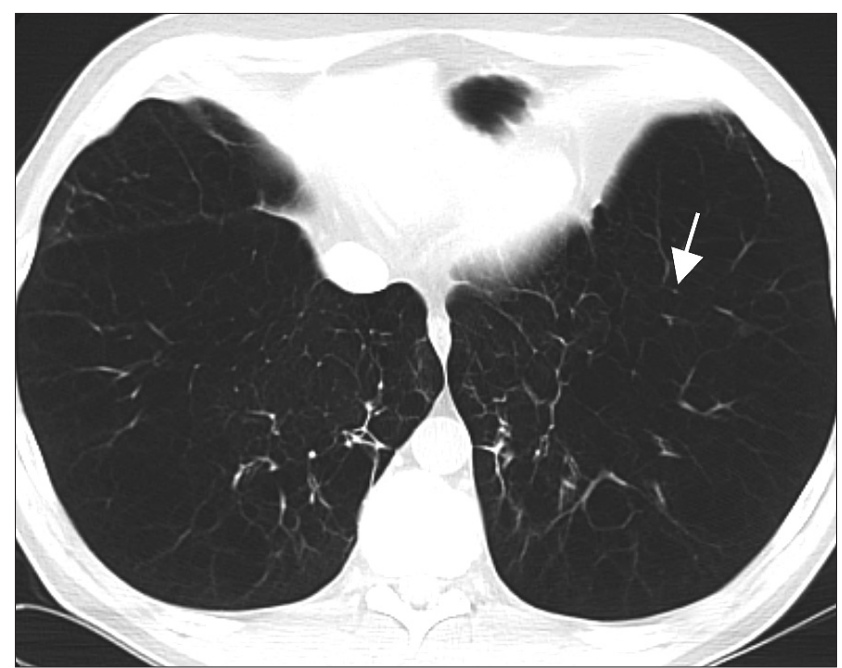

(a)

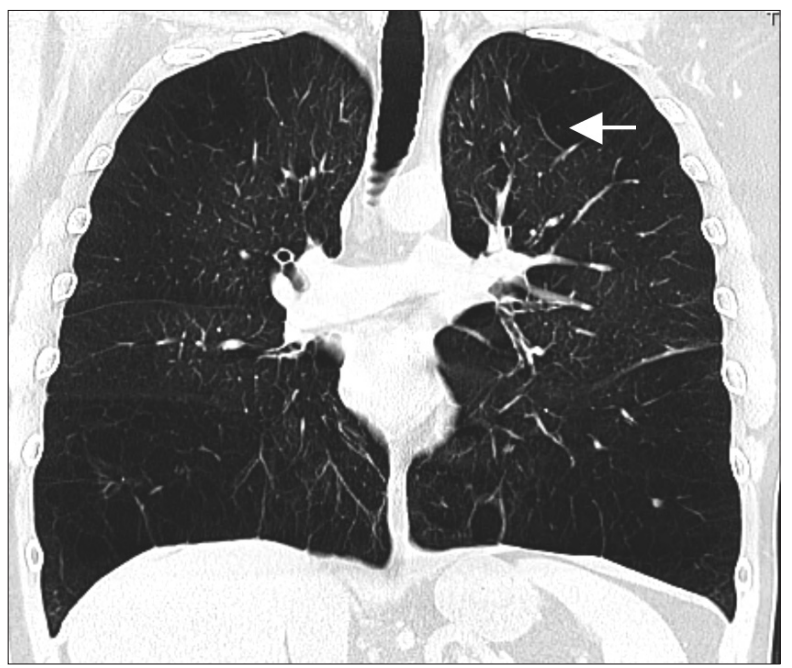

(b)

Fig. 8. - Axial (a) and coronal reformatted (b) CT images of a patient with alpha one antitrypsin deficiency showing lower lobe predominant panacinar emphysema. Note that the parenchymal destruction involves multiple secondary pulmonary lobules entirely. The centrilobular artery is also seen in middle of a few of these lucent areas (white arrows). 


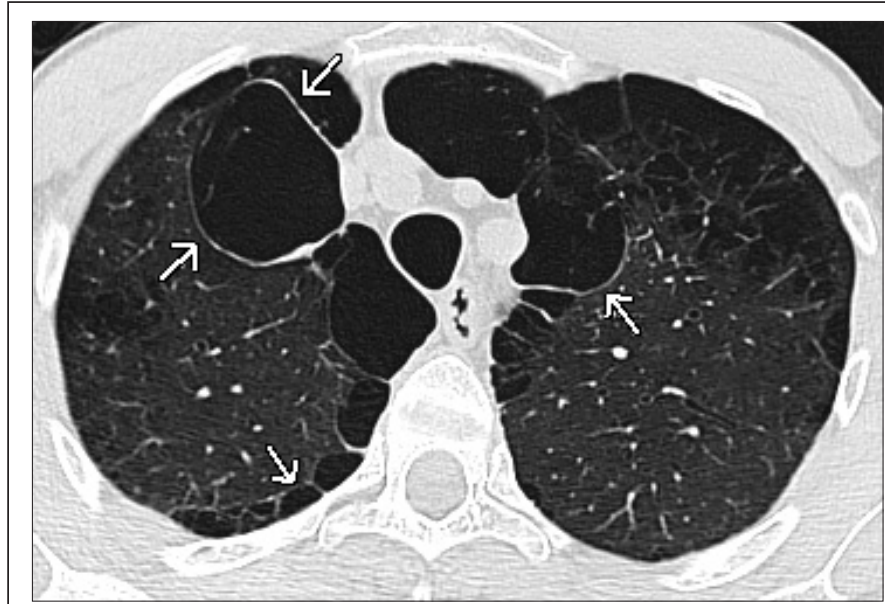

(a)

Fig. 9. - Axial (a) and coronal reformatted (b) CT images show upper lobe paraseptal emphysema. Note the subpleural location and elongated shape of the lucent areas with thin visible walls (arrow) that represent the surrounding interlobular septa. A few of these areas measure more than $1 \mathrm{~cm}$ in diameter, and are therefore termed bulla.

The interpretation of HRCT scans in patients with diffuse parenchymal lung diseases (DPLD) can be difficult, as findings may be nonspecific in $50 \%$ of cases $[87,88]$. While difficulty exists with diagnosing DPLDs overall, specialized thoracic radiologists can become quite good at interpreting HRCT scans of patients with IPF and other idiopathic interstitial pneumonias $[19,89,90]$. The positive predictive value of a HRCT diagnosis of UIP is $90-100 \%$ in several studies [91-93].

A multidisciplinary approach with review of the case by pulmonologists, pulmonary pathologists, and thoracic radiologists is most beneficial when evaluating these often times complicated patients. As discussed above, HRCT plays a key role in distinguishing a UIP pattern from other IIPs. The HRCT criteria for diagnosing UIP pattern is based in the presence of basal and subpleural predominant reticular abnormalities in conjunction with honeycombing and absence of findings that

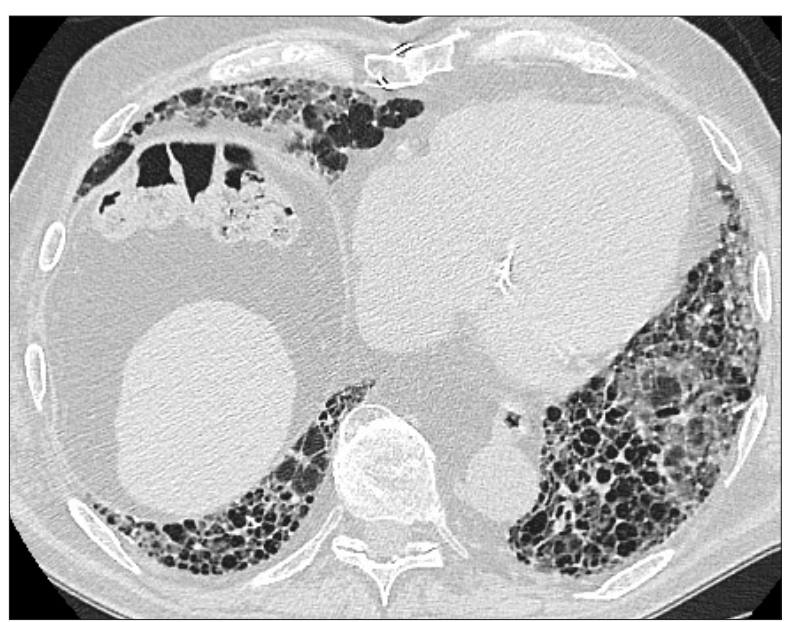

Fig. 10. - 71 year old male with biopsy proven idiopathic pulmonary fibrosis. Axial CT image shows peripheral and lower lobe predominant end-stage fibrotic changes with architectural distortion, traction bronchiectasis, and subpleural honeycombing.

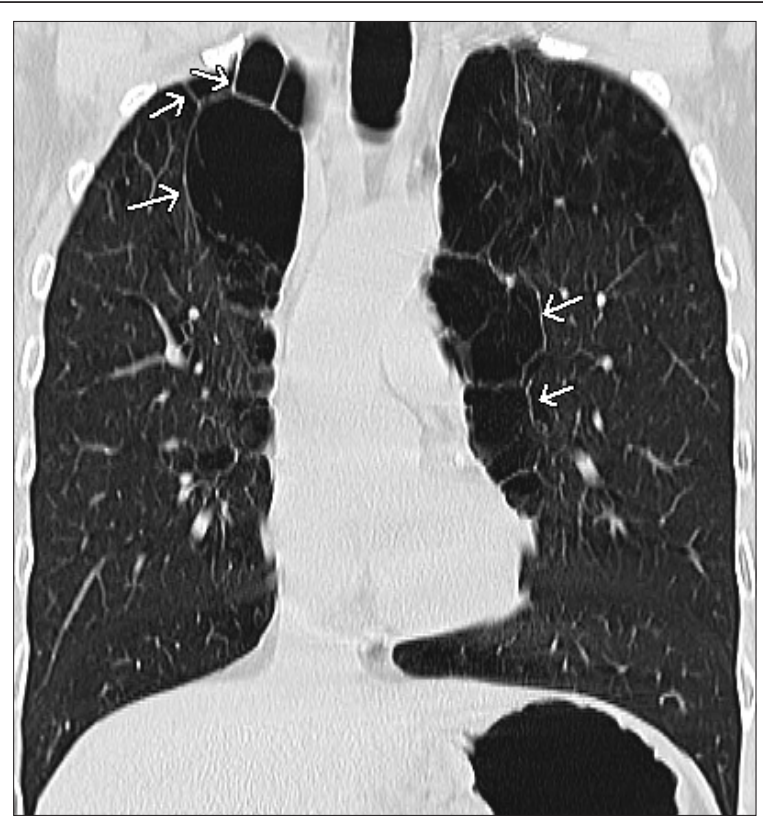

(b)

suggest an alternative diagnosis such as peribronchovascular predominance, extensive ground glass abnormality, discrete cysts, segmental/lobar consolidations, and diffuse mosaic attenuation [12].

In clinical practice, the visual assessment of disease extent by HRCT can be used in association with pulmonary function test results to monitor progression of IPF, as well as to evaluate response to therapy and aid with prognosis. This measurement should be made with intermediate interval follow-ups rather than short-term interval followup since longitudinal changes in HRCT scans during short-term follow-up are less predictive of survival when compared to physiologic measurements [94, 95].

Given that CT is accurate in diagnosing both pulmonary emphysema and fibrosis alone and that each distinct disease demonstrates different imaging characteristics, it is not difficult to make the diagnosis of CPFE using computed tomography of the chest. Patients demonstrate lucent areas of lung destruction in the upper lobes associated with lower lobe predominant reticular markings, honeycombing, and traction bronchiectasis that reflect underlying pulmonary fibrosis (fig. 11).

As discussed above, pulmonary arterial hypertension is seen in patients with emphysema and pulmonary fibrosis. Chest radiography of patients with PAH classically demonstrates the "pruned tree" appearance made by the enlargement of the central pulmonary arteries and abrupt decrease in caliber of the pulmonary vasculature peripherally (fig. 12). Chest CT of these patients can demonstrate enlargement of the central pulmonary arteries but this finding is neither specific nor sensitive. It may also show abrupt narrowing and tapering of the peripheral pulmonary vessels, right ventricular hypertrophy, right ventricular and right atrial enlargement, dilated bronchial arteries, and a mosaic pattern of attenuation due to variable lung perfusion (fig. 13) [96]. 


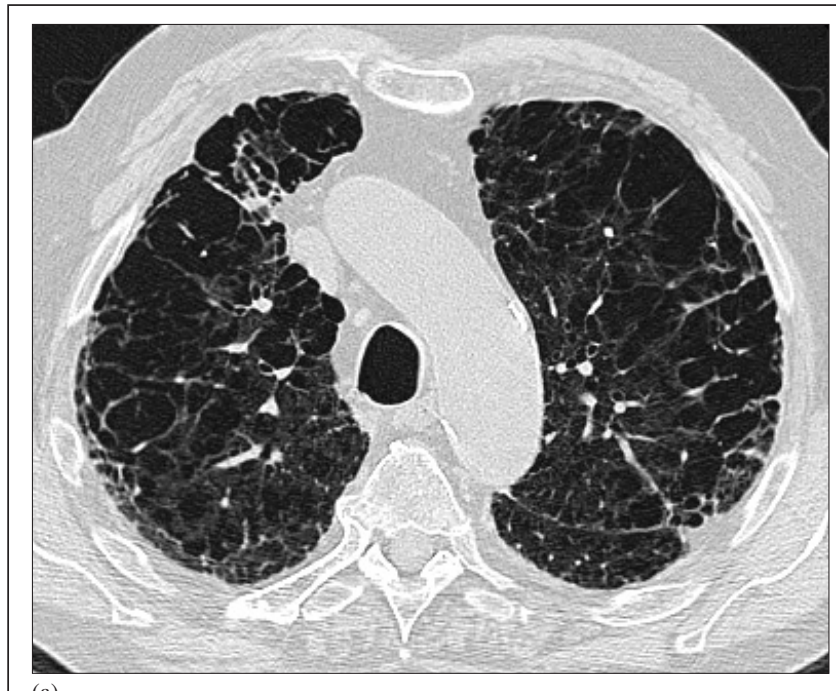

(a)

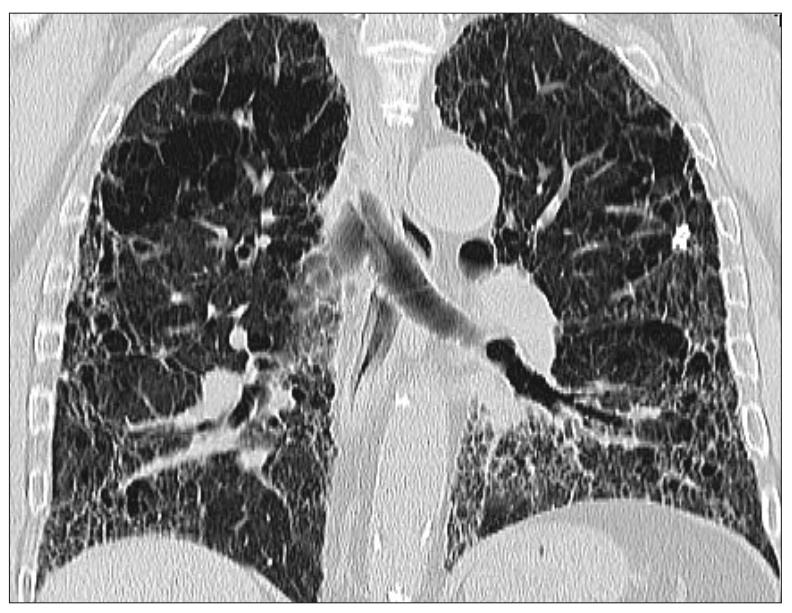

(c)

Fig. 11. - 60 year old female with smoking history, worsening shortness of breath and dry cough. Axial (a, b) and coronal reformatted (c) CT images showing the concomitant presence of upper lobe predominant emphysema with lucent areas of lung destrucion as well as peripheral and lower lobe predominant fibrotic changes seen as increased reticular markings and traction bronchiectasis.

IPF patients are also at increased risk of pulmonary embolism, which is likely secondary to endothelial damage. Chest CT, when tailored to evaluate the pulmonary arteries, is very sensitive and specific in diagnosing pulmonary embolism, especially when using multidetector CT scanners [97, 98]. Patients with pulmonary fibrosis are also at increased risk of developing bronchogenic carcinoma. CT is more sensitive than chest radiography at detecting lung cancer, and can pick them up when they are smaller and at an earlier stage [99-102].

\section{Radiation Considerations}

It is important to keep in mind that patients who undergo multiple serial CT scans are exposed to a higher cumulative radiation dose over time. Therefore the benefits and risks related to this exam should always be weighed prior to imaging. In the early days of CT, the radiation exposure could not be reduced, since the technology available at that time did not allow for a reduction in the dose

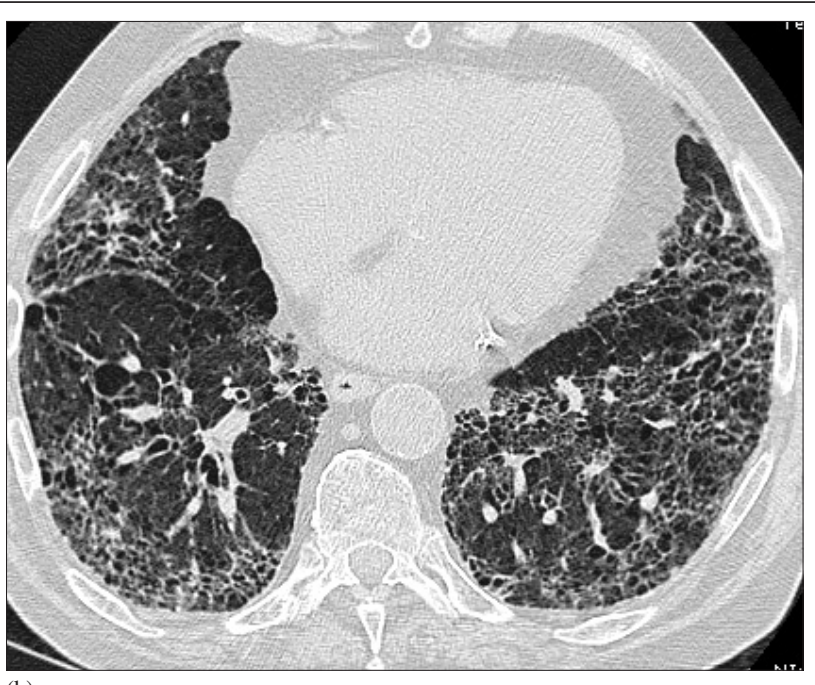

(b)

without increasing image noise. A large amount of image noise degrades image contrast and quality, thus impairing diagnostic accuracy [77]. With advancement of technology, the CT scanners are now able to produce the same image quality with a much lower radiation dose to the patient. While the risk of radiation is still dependent mostly on the patient's age, the body part that is being scanned, and how much of the patient's body is covered (length of the scan), the effective radiation dose received during a routine computed tomography of the chest is about $8 \mathrm{mSv}$, which is equivalent to approximately 100 chest X-rays [103].

In conclusion, combined pulmonary fibrosis and emphysema is an important but still underdiagnosed syndrome that has imaging findings of both pulmonary emphysema and fibrosis but is associated with a worse prognosis when compared to each of these diseases alone. Since radiology plays a key role in making this diagnosis, it is important that radiologists be familiar with the existence and appearance of this syndrome, which will facilitate early and accurate diagnosis to potentially improve prognosis.

\section{References}

1. Lopez AD, Shibuya K, Rao C, Mathers CD, Hansell AL, Held LS, et al. Chronic obstructive pulmonary disease: current burden and future projections. Eur Respir $J$ 2006; 27: 397-412.

2. Murray CJ, Lopez AD. Alternative projections of mortality and disability by cause 1990-2020: Global Burden of Disease Study. Lancet 1997; 349 (9065): 1498-504.

3. King TE, Jr., Tooze JA, Schwarz MI, Brown KR, Cherniack RM. Predicting survival in idiopathic pulmonary fibrosis: scoring system and survival model. Am $J$ Respir Crit Care Med 2001; 164: 1171-81.

4. Wiggins J, Strickland B, Turner-Warwick M. Combined cryptogenic fibrosing alveolitis and emphysema: the value of high resolution computed tomography in assessment. Respir Med 1990; 84: 365-9.

5. American Thoracic Society/European Respiratory Society International Multidisciplinary Consensus Classification of the Idiopathic Interstitial Pneumonias. This joint statement of the American Thoracic Society (ATS), and the European Respiratory Society (ERS) 

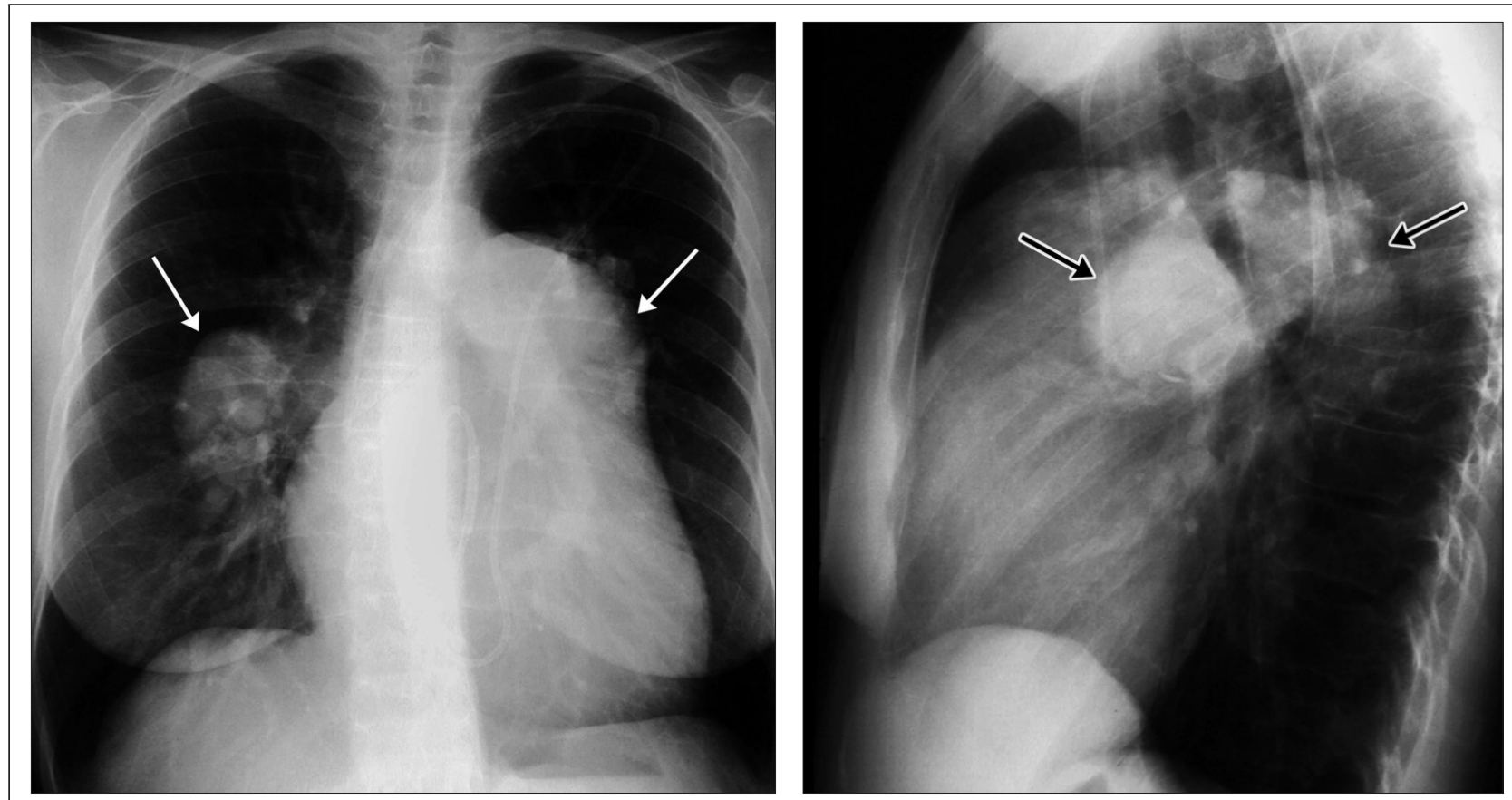

(a)

(b)

Fig. 12. - 87 years old male with history of chronic pulmonary arterial hypertension. Frontal (a) and lateral (b) radiographs of the chest demonstrate enlargement of the main pulmonary arterial trunk as well as the right and left pulmonary arteries (white and black arrows). Also note the "pruned-tree" appearance due to abrupt reduction in the caliber of the vessels in the peripheral two thirds of the lung, classically seen in this clinical setting.
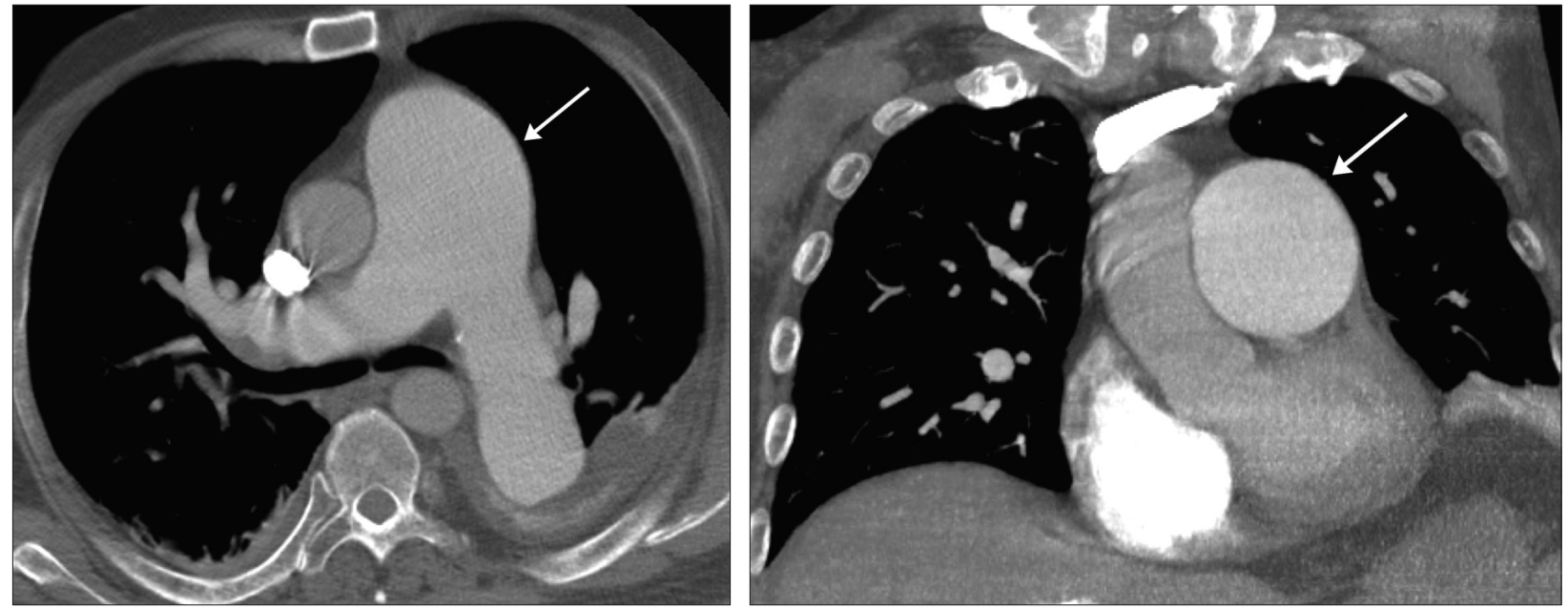

(a)

(b)

Fig. 13. - 87 years old male with history of chronic pulmonary arterial hypertension. Axial (a) and coronal reformatted (b) images from a contrastenhanced chest CT show the enlargement of the pulmonary arteries (white arrows).

was adopted by the ATS board of directors, June 2001 and by the ERS Executive Committee, June 2001. Am J Respir Crit Care Med 2002; 165: 277-304.

6. Kim DS, Collard HR, King TE, Jr. Classification and natural history of the idiopathic interstitial pneumonias. Proc Am Thorac Soc 2006; 3: 285-92.

7. Visscher DW, Myers JL. Histologic spectrum of idiopathic interstitial pneumonias. Proc Am Thorac Soc 2006; 3: 322-9.

8. Katzenstein AL, Myers JL. Idiopathic pulmonary fibrosis: clinical relevance of pathologic classification. Am J Respir Crit Care Med 1998; 157 (4 Pt 1): 1301-15.

9. Keane MP, Strieter RM, Lynch JP, 3rd, Belperio JA. Inflammation and angiogenesis in fibrotic lung disease. Semin Respir Crit Care Med 2006; 27: 589-99.

10. Schwartz DA, Helmers RA, Galvin JR, Van Fossen DS, Frees KL, Dayton CS, et al. Determinants of survival in idiopathic pulmonary fibrosis. Am J Respir Crit Care Med 1994; 149 (2 Pt 1): 450-4.

11. Selman M, King TE, Pardo A. Idiopathic pulmonary fibrosis: prevailing and evolving hypotheses about its pathogenesis and implications for therapy. Ann Intern Med 2001; 134: 136-51.

12. Raghu G, Collard HR, Egan JJ, Martinez FJ, Behr J, Brown KK, et al. An Official ATS/ERS/JRS/ALAT Statement: Idiopathic Pulmonary Fibrosis: Evidencebased Guidelines for Diagnosis and Management. Am J Respir Crit Care Med 2010; 183: 788-824.

13. Coultas DB, Zumwalt RE, Black WC, Sobonya RE. The epidemiology of interstitial lung diseases. $A m \mathrm{~J}$ Respir Crit Care Med 1994; 150: 967-72.

14. American Thoracic Society. Idiopathic pulmonary fibrosis: diagnosis and treatment. International consensus statement. American Thoracic Society (ATS), and the 
European Respiratory Society (ERS). Am J Respir Crit Care Med 2000; 161 (2 Pt 1): 646-64.

15. Raghu G, Weycker D, Edelsberg J, Bradford WZ, Oster G. Incidence and prevalence of idiopathic pulmonary fibrosis. Am J Respir Crit Care Med 2006; 174: 810-6.

16. Nadrous HF, Myers JL, Decker PA, Ryu JH. Idiopathic pulmonary fibrosis in patients younger than 50 years. Mayo Clin Proc 2005; 80: 37-40.

17. Iwai K, Mori T, Yamada N, Yamaguchi M, Hosoda Y. Idiopathic pulmonary fibrosis. Epidemiologic approaches to occupational exposure. Am J Respir Crit Care Med 1994; 150: 670-5.

18. Gribbin J, Hubbard RB, Le Jeune I, Smith CJ, West J, Tata LJ. Incidence and mortality of idiopathic pulmonary fibrosis and sarcoidosis in the UK. Thorax 2006; 61: 980-5.

19. Hunninghake GW, Lynch DA, Galvin JR, Gross BH, Muller N, Schwartz DA, et al. Radiologic findings are strongly associated with a pathologic diagnosis of usual interstitial pneumonia. Chest 2003; 124: 1215-23.

20. Martinez FJ, Safrin S, Weycker D, Starko KM, Bradford WZ, King TE, Jr., et al. The clinical course of patients with idiopathic pulmonary fibrosis. Ann Intern Med 2005; 142 (12 Pt 1): 963-7.

21. Horowitz JC, Thannickal VJ. Idiopathic pulmonary fibrosis: new concepts in pathogenesis and implications for drug therapy. Treat Respir Med 2006; 5: 325-42.

22. Weitzenblum E, Ehrhart M, Rasaholinjanahary J, Hirth C. Pulmonary hemodynamics in idiopathic pulmonary fibrosis and other interstitial pulmonary diseases. Respiration 1983; 44: 118-27.

23. Newman JH. Pulmonary hypertension. Am J Respir Crit Care Med 2005; 172: 1072-7.

24. Panos RJ, Mortenson RL, Niccoli SA, King TE, Jr. Clinical deterioration in patients with idiopathic pulmonary fibrosis: causes and assessment. Am J Med 1990; 88: 396-404.

25. Murray CJ, Lopez AD. Evidence-based health policy lessons from the Global Burden of Disease Study. Science 1996; 274 (5288): 740-3.

26. Mathers CD, Loncar D. Projections of global mortality and burden of disease from 2002 to 2030. PLoS Med 2006; 3: e442.

27. Deaths from chronic obstructive pulmonary disease United States, 2000-2005. MMWR Morb Mortal Wkly Rep 2008; 57: 1229-32.

28. Mannino DM, Homa DM, Akinbami LJ, Ford ES, Redd SC. Chronic obstructive pulmonary disease surveillance - United States, 1971-2000. MMWR Surveill Summ 2002; 51: 1-16.

29. Celli BR, Halbert RJ, Isonaka S, Schau B. Population impact of different definitions of airway obstruction. Eur Respir J 2003 22: 268-73.

30. Menezes AM, Perez-Padilla R, Jardim JR, et al. Chronic obstructive pulmonary disease in five Latin American cities (the PLATINO study): a prevalence study. Lancet 2005; 366 (9500): 1875-81.

31. Pena VS, Miravitlles M, Gabriel R, et al. Geographic variations in prevalence and underdiagnosis of COPD: results of the IBERPOC multicentre epidemiological study. Chest 2000; 118: 981-9.

32. Tzanakis N, Anagnostopoulou U, Filaditaki V, Christaki P, Siafakas N. Prevalence of COPD in Greece. Chest 2004; 125: 892-900.

33. de Marco R, Accordini S, Cerveri I, et al. An international survey of chronic obstructive pulmonary disease in young adults according to GOLD stages. Thorax 2004; 59: 120-5.

34. Talamo C, de Oca MM, Halbert R, et al. Diagnostic labeling of COPD in five Latin American cities. Chest 2007; 131: 60-7.

35. Damarla M, Celli BR, Mullerova HX, Pinto-Plata VM. Discrepancy in the use of confirmatory tests in patients hospitalized with the diagnosis of chronic obstructive pulmonary disease or congestive heart failure. Respir Care 2006; 51: 1120-4.

36. Pauwels RA, Buist AS, Calverley PM, Jenkins CR, Hurd SS. Global strategy for the diagnosis, management, and prevention of chronic obstructive pulmonary disease. NHLBI/WHO Global Initiative for Chronic Obstructive Lung Disease (GOLD) Workshop summary. Am J Respir Crit Care Med 2001; 163: 1256-76.

37. Prescott E. Tobacco-related diseases: the role of gender. An epidemiologic study based on data from the Copenhagen Centre for Prospective Population Studies. Dan Med Bull 2000; 47: 115-31.

38. Celli BR, MacNee W. Standards for the diagnosis and treatment of patients with COPD: a summary of the ATS/ERS position paper. Eur Respir $J$ 2004; 23 : 932-46.

39. Rennard SI. Inflammation and repair processes in chronic obstructive pulmonary disease. Am J Respir Crit Care Med 1999; 160 (5 Pt 2): S12-6.

40. Peinado VI, Barbera JA, Abate P, et al. Inflammatory reaction in pulmonary muscular arteries of patients with mild chronic obstructive pulmonary disease. Am J Respir Crit Care Med 1999; 159 (5 Pt 1): 1605-11.

41. Matsuba K, Wright JL, Wiggs BR, Pare PD, Hogg JC. The changes in airways structure associated with reduced forced expiratory volume in one second. Eur Respir J 1989; 2: 834-9.

42. Kitaguchi Y, Fujimoto K, Kubo K, Honda T. Characteristics of COPD phenotypes classified according to the findings of HRCT. Respir Med 2006; 100: 1742-52.

43. Snider GL, Kleinerman J, Thurlbeck WM, Bengali ZH. The definition of emphysema. Report of a National Heart, Lung, and Blood Institute, Division of Lung Diseases workshop. Am Rev Respir Dis 1985; 132: 182-5.

44. Stern EJ, Frank MS, Schmutz JF, Glenny RW, Schmidt RA, Godwin JD. Panlobular pulmonary emphysema caused by i.v. injection of methylphenidate (Ritalin): findings on chest radiographs and CT scans. Am J Roentgenol 1994; 162: 555-60.

45. Fisher MR, Criner GJ, Fishman AP, et al. Estimating pulmonary artery pressures by echocardiography in patients with emphysema. Eur Respir J 2007; 30: 914-21.

46. Scharf SM, Iqbal M, Keller C, Criner G, Lee S, Fessler HE. Hemodynamic characterization of patients with severe emphysema. Am J Respir Crit Care Med 2002; 166: 314-22.

47. Hoyle GW, Li J, Finkelstein JB, et al. Emphysematous lesions, inflammation, and fibrosis in the lungs of transgenic mice overexpressing platelet-derived growth factor. Am J Pathol 1999; 154: 1763-75.

48. Lucattelli M, Bartalesi B, Cavarra E, et al. Is neutrophil elastase the missing link between emphysema and fibrosis? Evidence from two mouse models. Respir Res 2005; 6: 83.

49. Lundblad LK, Thompson-Figueroa J, Leclair T, et al. Tumor necrosis factor-alpha overexpression in lung disease: a single cause behind a complex phenotype. Am J Respir Crit Care Med 2005; 171: 1363-70.

50. Cottin V, Nunes H, Brillet PY, et al. Combined pulmonary fibrosis and emphysema: a distinct underrecognised entity. Eur Respir J 2005; 26: 586-93.

51. Kosacka M, Brzecka A, Jankowska R, Lewczuk J, Mroczek E, Werynska B. Combined pulmonary fibrosis and emphysema - case report and literature review. Pneumonol Alergol Pol 2009; 77: 205-10.

52. Cottin V, Brillet PY, Nunes H, Cordier JF. Combined pulmonary fibrosis and emphysema. Presse Med 2007; 36 (6 Pt 2): 936-44.

53. Schwartz DA, Merchant RK, Helmers RA, Gilbert SR, Dayton CS, Hunninghake GW. The influence of cigarette smoking on lung function in patients with idio- 
pathic pulmonary fibrosis. Am Rev Respir Dis 1991; 144 (3 Pt 1): 504-6.

54. Hiwatari N, Shimura S, Takishima T. Pulmonary emphysema followed by pulmonary fibrosis of undetermined cause. Respiration 1993; 60: 354-8.

55. Parry RA, Glaze SA, Archer BR. The AAPM/RSNA physics tutorial for residents. Typical patient radiation doses in diagnostic radiology. Radiographics 1999; 19: 1289-302.

56. Reich SB, Weinshelbaum A, Yee J. Correlation of radiographic measurements and pulmonary function tests in chronic obstructive pulmonary disease. Am J Roentgenol 1985; 144: 695-9.

57. Standards for the diagnosis and care of patients with chronic obstructive pulmonary disease (COPD) and asthma. This official statement of the American Thoracic Society was adopted by the ATS Board of Directors, November 1986. Am Rev Respir Dis 1987; 136: 225-44.

58. Burki NK. Roentgenologic diagnosis of emphysema. Accurate or not? Chest 1989; 95: 1178-9.

59. Foster WL, Jr., Gimenez EI, Roubidoux MA, et al. The emphysemas: radiologic-pathologic correlations. Radiographics 1993; 13: 311-28.

60. Pratt PC. Role of conventional chest radiography in diagnosis and exclusion of emphysema. Am J Med 1987; 82: 998-1006.

61. Thurlbeck WM, Muller NL. Emphysema: definition, imaging, and quantification. Am J Roentgenol 1994; 163: 1017-25.

62. Epler GR, McLoud TC, Gaensler EA, Mikus JP, Carrington $\mathrm{CB}$. Normal chest roentgenograms in chronic diffuse infiltrative lung disease. N Engl J Med 1978; 298: 934-9.

63. Carrington CB, Gaensler EA, Coutu RE, FitzGerald MX, Gupta RG. Natural history and treated course of usual and desquamative interstitial pneumonia. $N$ Engl J Med 1978; 298: 801-9.

64. Hurwitz LM, Reiman RE, Yoshizumi TT, et al. Radiation dose from contemporary cardiothoracic multidetector CT protocols with an anthropomorphic female phantom: implications for cancer induction. Radiology 2007; 245: 742-50.

65. Henschke CI, Boffetta P, Gorlova O, Yip R, Delancey J, Foy M. Assessment of lung-cancer mortality reduction from CT Screening. Lung Cancer 2011; 71: 328-32.

66. Foster WL, Jr., Pratt PC, Roggli VL, Godwin JD, Halvorsen RA, Jr., Putman CE. Centrilobular emphysema: CTpathologic correlation. Radiology 1986; 159: 27-32.

67. Hruban RH, Meziane MA, Zerhouni EA, et al. High resolution computed tomography of inflation-fixed lungs. Pathologic-radiologic correlation of centrilobular emphysema. Am Rev Respir Dis 1987; 136: 935-40.

68. Webb WR, Stein MG, Finkbeiner WE, Im JG, Lynch D, Gamsu G. Normal and diseased isolated lungs: highresolution CT. Radiology 1988; 166 (1 Pt 1): 81-7.

69. Webb WR. Thin-section CT of the secondary pulmonary lobule: anatomy and the image - the 2004 Fleischner lecture. Radiology 2006; 239: 322-38.

70. Goddard PR, Nicholson EM, Laszlo G, Watt I. Computed tomography in pulmonary emphysema. Clin Radiol 1982; 33: 379-87.

71. Hersh CP, Washko GR, Jacobson FL, et al. Interobserver variability in the determination of upper lobepredominant emphysema. Chest 2007; 131: 424-31.

72. Boedeker KL, McNitt-Gray MF, Rogers SR, et al. Emphysema: effect of reconstruction algorithm on CT imaging measures. Radiology 2004; 232: 295-301.

73. Gevenois PA, de Maertelaer V, De Vuyst P, Zanen J, Yernault JC. Comparison of computed density and macroscopic morphometry in pulmonary emphysema. Am J Respir Crit Care Med 1995; 152: 653-7.
74. Gevenois PA, Scillia P, de Maertelaer V, Michils A, De Vuyst P, Yernault JC. The effects of age, sex, lung size, and hyperinflation on CT lung densitometry. Am $J$ Roentgenol 1996; 167: 1169-73.

75. Parr DG, Stoel BC, Stolk J, Nightingale PG, Stockley RA. Influence of calibration on densitometric studies of emphysema progression using computed tomography. Am J Respir Crit Care Med 2004; 170: 883-90.

76. Stoel BC, Bakker ME, Stolk J, et al. Comparison of the sensitivities of 5 different computed tomography scanners for the assessment of the progression of pulmonary emphysema: a phantom study. Invest Radiol 2004; 39: 1-7.

77. Yuan R, Mayo JR, Hogg JC, et al. The effects of radiation dose and CT manufacturer on measurements of lung densitometry. Chest 2007; 132: 617-23.

78. Kuwano K, Matsuba K, Ikeda T, et al. The diagnosis of mild emphysema. Correlation of computed tomography and pathology scores. Am Rev Respir Dis 1990; 141: 169-78.

79. Bergin CJ, Muller NL, Miller RR. CT in the qualitative assessment of emphysema. J Thorac Imaging 1986; 1: 94-103.

80. Kinsella M, Muller NL, Abboud RT, Morrison NJ, DyBuncio A. Quantitation of emphysema by computed tomography using a "density mask" program and correlation with pulmonary function tests. Chest 1990; 97: 315-21.

81. Sakai F, Gamsu G, Im JG, Ray CS. Pulmonary function abnormalities in patients with CT-determined emphysema. J Comput Assist Tomogr 1987; 11: 963-8.

82. Nishimura K, Murata K, Yamagishi M, et al. Comparison of different computed tomography scanning methods for quantifying emphysema. $J$ Thorac Imaging 1998; 13: 193-8.

83. Staples CA, Muller NL, Vedal S, Abboud R, Ostrow D, Miller RR. Usual interstitial pneumonia: correlation of CT with clinical, functional, and radiologic findings. Radiology 1987; 162: 377-81.

84. Terriff BA, Kwan SY, Chan-Yeung MM, Muller NL. Fibrosing alveolitis: chest radiography and CT as predictors of clinical and functional impairment at followup in 26 patients. Radiology 1992; 184: 445-9.

85. Lynch DA, Godwin JD, Safrin S, et al. High-resolution computed tomography in idiopathic pulmonary fibrosis: diagnosis and prognosis. Am J Respir Crit Care Med 2005; 172: 488-93.

86. MacDonald SL, Rubens MB, Hansell DM, et al. Nonspecific interstitial pneumonia and usual interstitial pneumonia: comparative appearances at and diagnostic accuracy of thin-section CT. Radiology 2001; 221: 600-5.

87. Souza CA, Muller NL, Flint J, Wright JL, Churg A. Idiopathic pulmonary fibrosis: spectrum of high-resolution CT findings. Am J Roentgenol 2005; 185: 1531-9.

88. Johkoh T, Muller NL, Cartier Y, et al. Idiopathic interstitial pneumonias: diagnostic accuracy of thin-section CT in 129 patients. Radiology 1999; 211: 555-60.

89. Hunninghake GW, Zimmerman MB, Schwartz DA, et $a l$. Utility of a lung biopsy for the diagnosis of idiopathic pulmonary fibrosis. Am J Respir Crit Care Med 2001; 164: 193-6.

90. Raghu G, Mageto YN, Lockhart D, Schmidt RA, Wood DE, Godwin JD. The accuracy of the clinical diagnosis of new-onset idiopathic pulmonary fibrosis and other interstitial lung disease: A prospective study. Chest 1999; 116: 1168-74.

91. Mathieson JR, Mayo JR, Staples CA, Muller NL. Chronic diffuse infiltrative lung disease: comparison of diagnostic accuracy of $\mathrm{CT}$ and chest radiography. Radiology 1989; 171: 111-6.

92. Grenier P, Valeyre D, Cluzel P, Brauner MW, Lenoir S, Chastang C. Chronic diffuse interstitial lung disease: 
diagnostic value of chest radiography and high-resolution CT. Radiology 1991; 179: 123-32.

93. Lee KS, Primack SL, Staples CA, Mayo JR, Aldrich JE, Muller NL. Chronic infiltrative lung disease: comparison of diagnostic accuracies of radiography and low- and conventional-dose thin-section CT. Radiology 1994; 191: 669-73.

94. Battista G, Zompatori M, Fasano L, Pacilli A, Basile B. Progressive worsening of idiopathic pulmonary fibrosis. High resolution computed tomography (HRCT) study with functional correlations. Radiol Med 2003; 105: 2-11.

95. Flaherty KR, Mumford JA, Murray S, et al. Prognostic implications of physiologic and radiographic changes in idiopathic interstitial pneumonia. Am J Respir Crit Care Med 2003; 168: 543-8.

96. Grosse C, Grosse A. CT findings in diseases associated with pulmonary hypertension: a current review. Radiographics 30: 1753-77.

97. Patel S, Kazerooni EA. Helical CT for the evaluation of acute pulmonary embolism. AJR Am J Roentgenol 2005; 185: $135-49$.
98. Mamlouk MD, vanSonnenberg E, Gosalia R, et al. Pulmonary embolism at CT angiography: implications for appropriateness, cost, and radiation exposure in 2003 patients. Radiology 256: 625-32.

99. Henschke CI, McCauley DI, Yankelevitz DF, et al. Early Lung Cancer Action Project: overall design and findings from baseline screening. Lancet 1999; 354 (9173): 99-105.

100. Henschke CI, Yankelevitz DF, Libby DM, Pasmantier MW, Smith JP, Miettinen OS. Survival of patients with stage I lung cancer detected on CT screening. $N$ Engl J Med 2006; 355: 1763-71.

101. Foy M, Yip R, Chen X, Kimmel M, Gorlova OY, Henschke CI. Modeling the mortality reduction due to computed tomography screening for lung cancer. Cancer 2011; 117: 2703-8.

102. http: //www.cancer.gov/newscenter/pressreleases/NLSTresultsRelease.

103. Brix G, Nagel HD, Stamm G, et al. Radiation exposure in multi-slice versus single-slice spiral CT: results of a nationwide survey. Eur Radiol 2003; 13: 1979-91.

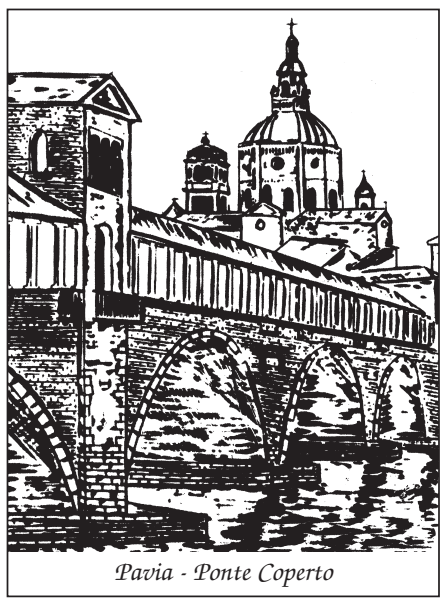

